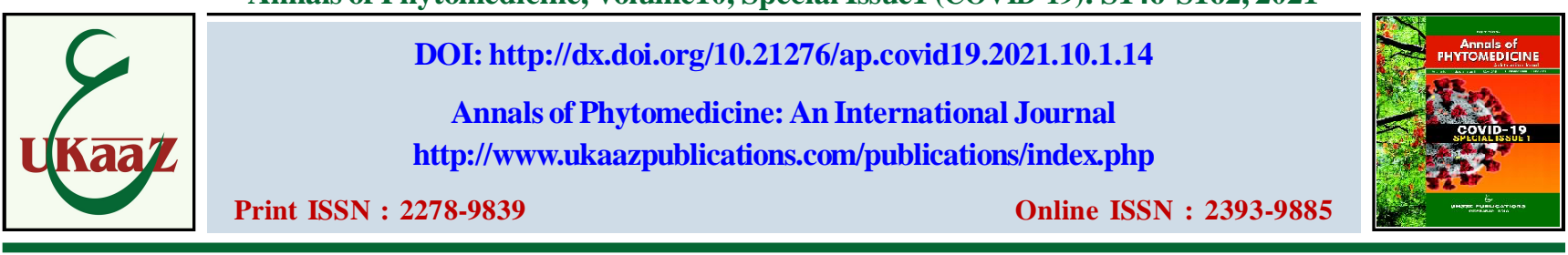

\title{
Role and significance of fruits in boosting immunity against COVID-19 infections
}

\author{
A. Indhuleka , R. Sanjana*, J. Janet and V. Ragavi \\ Department of Science and Humanities, Sri Krishna College of Engineering and Technology, Coimbatore-641008, Tamilnadu, India \\ *Department of Business Management, Sheffield Hallam University, Sheffield, United Kingdom
}

\begin{tabular}{l} 
Article Info \\
\hline Article history \\
Received 11 May 2021 \\
Revised 26 June 2021 \\
Accepted 27 June 2021 \\
Published Online 30 June 2021
\end{tabular}

\section{Keywords}

COVID-19

Functional foods

Fruits

Antioxidant

Immune health

\begin{abstract}
Novel coronavirus disease-19 (COVID-19) has been declared as a world pandemic which is responsible for high mortality rate. Finding a clinical cure for the same is difficult due to its variable characteristics. Thus, prevention is the most adaptive way to improve the current pandemic situation. Various studies suggest that patients with compromised immune health are the most susceptible host for this virus. This can be overcome by consumption of functional foods rich in nutritional components that boosts the human immune health. Recommended diet to improve the functioning of immune system includes vegetables, fruits, legumes, etc. They contain high quantities of protein, vitamins, minerals and phytochemicals that enhance the antioxidant and anti-inflammatory capabilities. Nutraceutical rich fruits like apples, papayas, citrus, berries and pineapples are under consideration to boost the immunity and keep the infections at bay. Apart from dietary supplementation, a good sleep combined with exercise routine can enhance the functioning of immune system and decrease the viral impact to a greater extent.
\end{abstract}

\section{Introduction}

\subsection{Coronavirus and importance of enhancing the immunity}

The first case of coronavirus, (SARS-CoV-2) was found in Wuhan, China during December 2019. From then, the virus has spread all over the world, making it a world-wide pandemic which caused millions of deaths and still counting. This viral infection is more susceptible to elders and babies whose immune strength is weak (Zhu et al., 2020). This virus is an enveloped single stranded RNA that is classified as alpha, beta, delta and gamma; of which alpha and beta is the main cause for COVID-19. Coronavirus primarily attacks the respiratory tract and destroys the epithelial cells. This causes cough, breathing difficulty, onset of fever, fatigue, etc., as symptoms (Huang et al., 2020). Transmission of the virus happens through human contact via the infected droplets of the COVID-19 patients while performing actions such as talking, sneezing, coughing, etc. Thus, minimizing the contact and wearing masks and other protective equipment reduces the contractibility. Therapeutic treatment suggests the usage of antiviral drugs and application of vaccines. With ongoing research on the latter, prevention of the viral outbreak by nutrient-rich diet is the most advisable form of strengthening immune system that is supplied by taking in more of vegetables, whose importance has been reviewed in detail by Indhuleka et al. (2021).

Evidences show that it is difficult for the viral load to enter into the system of people with strong immune health. Foods possessing antiviral and immune boosting capacities work in many mechanisms

Corresponding author: Dr. Indhuleka
Professor, Department of Science and Humanities, Sri Krishna College
of Engineering and Technology, Coimbatore-641008, Tamilnadu,
India
E-mail: indhuleka@gmail.com
Tel.: +91-9944633778

Copyright (c) 2021 Ukaaz Publications. All rights reserved.

Email: ukaaz@yahoo.com; Website: www.ukaazpublications.com to deter the virus by boosting the immune system, fastening the antiviral functioning inside the body and reducing the complications of the virus attack on body parts. Fruits and vegetables have positive effect on the human body by alleviating many chronic ailments like cardiovascular disease (CVD), diabetes, respiratory disorders, cancer, etc. The complete nutraceutical effect can be experienced by a complex vitamin, minerals, polyphenols, terpenoids, flavonoids, etc. (Alkhatib et al., 2017). Fruits are rich in vitamins A, B, C, D, E and minerals like zinc, selenium, magnesium, iron, etc., that boost the immunoprotective properties. Fermented foods and fruit juices increase the good gut microbiota which improves the immune health. They reduce the harsh effects of cancers, CVD and other metabolic disorders (Kang et al., 2005). Reactive oxygen species are produced due to various enzymatic reactions happening inside the body. This decreases the efficacy of the immune system and weakens it. Thus, scavenging of these radicals are vital to improve this condition, where comes the play of antioxidants. Antioxidants are rich in various fruits. All these compounds work in such a way that they modify the metabolism or mechanism of the pathogens, thus restricting the replication and production process of the virus. Some of the fruits reviewed on their basic nutritional properties and their mechanism to boost immune health are apples, papaya, pineapples, olives, citrus and berries, etc.

\section{Nutraceuticals in fruits}

Nutraceuticals are compounds that exert health benefits to human health. These compounds are extracted from the food and can be consumed as a part of daily diet to prevent the attack of some serious disorders. Some of such nutraceuticals that boost immunity in human are in the form of functional products like fibre, vitamins, polyphenols, etc. Studies suggest that these polyphenols act as antioxidants that hinder the pathways of chronic ailments (Siriwardhana et al., 2013). 


\subsection{Dietary fibres}

Fibres are complex carbohydrates that are rich in fruits, vegetables, nuts and legumes. Consumption of these in the right amount has many health benefits. They also improve the gut microbiome. These in turn produces SCFA-short chain fatty acids that are vital in immunomodulatory mechanisms (Tan et al., 2014). They also regulate inflammatory actions. Not just by increasing the favourable microbes, they also destroy the pathogenic microbes and improve the immune health. This maintains good functioning of the nasal and respiratory tract. Increased immune cells in mice are observed when injected with probiotics. Studies conducted reveal that consumption of extra $10 \mathrm{~g}$ of fibre reduced the risk of respiratory ailments by $34 \%$ (Kan et al., 2008).

\subsection{Vitamins}

\subsubsection{Vitamin A}

Carotenoids are one of the important sources of vitamin A. They play an important role in keratinization, differentiation, stratification and defence in human body. They form mucous layer important for enhancing antigen non-specific immunity functions (McCullough et al., 1999). Retinoic acid is another active form of vitamin A which promotes the activation of NK immune cells. This acid also regulates adaptive immune system (Worbs et al., 2017). Thus, a diet rich of vitamin $\mathrm{A}$ is always required to combat COVID-19 and such viral infections.

\subsubsection{Vitamin B}

Vitamin B complex is a rich set of vitamins that performs various functions in body regulation. Vitamin B2 along with UV radiations was used to reduce the viral load in MERS-CoV. Vitamin B1 and B3 induces the production of some or all of IL-1 $\beta$, IL-1, IL-6, COX-2, and TNF- $\alpha$. Vitamin B3 is used in the treatment of lung inflammation. Vitamin B6 is related to humoral and cell-mediated immunity. Vitamin B12 acts as an immunomodulator. Research shows that AIDS patients showed deficiency in vitamin B complex (Poudel-Tandukar and Chandyo, 2016).

\subsubsection{Vitamin C}

Vitamin $\mathrm{C}$ in the form of ascorbic acid, is the most important vitamin to enhance immunity in the body cells. It has high radical scavenging capabilities making it a natural antioxidant. They perform as a cofactor for many immunomodulatory pathways (Carr et al., 2015). Ascorbic acid plays a role in maturation and differentiation of Tcells, NK cells and they also stimulate neutrophil production (Huijsken et al., 2015). People affected with cold, pneumonia and major respiratory ailments showed vitamin $\mathrm{C}$ deficiency. Thus, consumption of vitamin $\mathrm{C}$ via daily diet is highly essential to maintain a good immune health.

\subsubsection{Vitamin D}

Calcitriol, the active form of vitamin D looks after the bone health. It also regulates the immune health by expressing the T-cells which can perform only after binding to the calcitriol (Mosekilde, 2005). Vitamin D also stimulates the action of other immune cells. The immune modulatory effects of vitamin D include, fighting directly against microbes, monocytes and other innate antigen presenting cells (APC), in particular dendritic cells (DC). APC are responsible for the initiation of the adaptive immune response by presenting the antigens to $\mathrm{T}$ cells and $\mathrm{B}$ cells and are able to modulate them by either immunogenic or tolerogenic signals such as cytokines and expression of co-stimulatory molecules. Studies show that vitamin D supplementation reduces the number of SARS-CoV-2 virus particles from attaching to the body cells.

\subsubsection{Vitamin $\mathrm{E}$}

Vitamin E is made of tocopherols and tocotrienols. They are important in the protection of influenza like infections (Meydani et al., 2005). Vitamin E along with vitamin C synergistically shows many health benefits. They act as antioxidants and reduce the oxidative stress; also shows anti-inflammatory activities. Vitamin $\mathrm{E}$ regulates the innate and adaptive immune system by increasing the NK, B, T immune cells (Marko et al., 2007).

\subsection{Minerals}

\subsubsection{Zinc}

Zinc deficiency is proven to increase the susceptibility of viral infections. The un-chelated zinc form shows antiviral activity. This element is vital for the differentiation of immune cells. Zinc helps in proliferation of CD8 + t-cell; which is an important cell in boosting immunity (Wintergerst et al., 2007). It acts as co-factor for many enzymes that functions for antioxidant. Studies suggest that pneumonia attacks patients with zinc deficiency (Barnet et al., 2010). Supplementation of zinc reduced the symptoms of cold and flu.

\subsubsection{Iron}

Vitamin A and iron deficiency go hand-in-hand since vitamin A modulates iron metabolism. Iron is an important element in proper DNA functioning. Iron also helps in proliferation of T-lymphocytes (Alpert, 2017). Antibody production is improved in system by having adequate levels of iron intake. This strengthens the innate and adaptive immunity in the body.

\subsubsection{Selenium}

Selenium is important in antioxidant actions. They proliferate Tlymphocyte involved in immunoglobin production during the attack of pathogens (Saeed et al., 2016). Selenium improves the vaccine response. This element is directly connected to innate immunity.

\subsection{Polyphenols}

Polyphenols are a group of secondary plant metabolites. They have at least one aromatic ring along with more hydroxyl groups. These polyphenols are grouped according to their chemical structures as flavonoids, flavanones, flavans, flavanols, anthocyanidins, proanthocyanidins, dihydroflavonols, isoflavones, flavan-3-ol and non-flavonoids (benzoic acids, xanthones, stilbenes, chalcones, lignans, benzophenones, coumarins, simple phenols, hydrolysable tannins, benzoic and cinnamic acids).

\subsection{Flavonoids}

Flavonoids comprise of benzoic ring with pyran rings. They are divided as flavonols and flavanols. These are mainly present in citrus and berry fruits. Flavanones are comprised of hesperetin, naringenin, eriodictyol, naringin, neohesperidin, narirutin, and 
hesperidin (Ren et al., 2016). Naringenin regulates the glucose levels and maintains lipid profile. They also intrude the cell proliferation of cancer cells which reduce the risk of cancer (Gupta et al., 2014). Quercetin is rich in strawberries and raspberries with high antioxidant capacity. This compound reduces the risk of asthma, diabetes and cancer (Knekt et al., 2002). Catechin reduces the oxidative stress. Epicatechin improves insulin secretion, thereby regulating diabetes and obesity (Cremonini et al., 2016). Anthocyanins are responsible for the colour of the fruits. They decrease the oxidative damage of protein and DNA by scavenging the radicals (Thilavech et al., 2016). They also induce apoptosis and reduce the risk of cancer. The fruits containing these components are recommended for cancer patients in their diet.

\section{Immunity boosting fruits}

Table 1: Fruits and their active ingredients in boosting immunity

\begin{tabular}{|c|c|c|c|}
\hline Fruit (Common name) & Scientific name & Family & Active ingredient boosting immunity \\
\hline Dates & Phoenix dactylifera $\mathrm{L}$. & Palmaceae & Vitamin A, flavonoids, iron \\
\hline Olive & Olea europaea $\mathrm{L}$. & Oleaceae & Vitamin E, triterpenoids, PUFA \\
\hline Passion fruit & Passiflora edulis & Passifloraceae & Vitamin A. vitamin C \\
\hline Persimmon & Diospyros kaki L. & Ebenaceae & Vitamin C, vitamin E, tannins, phenolic acid \\
\hline Pineapple & Ananas comosus $\mathrm{L}$. & Bromeliaceae & Vitamin $\mathrm{C}$, bromelain, flavonoids, malic acid \\
\hline Papaya & Carica papaya $\mathrm{L}$. & Caricaceae & Ascorbic acid, papain, proteolytic enzymes \\
\hline Dragon fruit & Selenicereus undatus & Cactaceae & $\begin{array}{l}\text { Vitamin C, vitamin D, zinc, carotenoids, } \\
\text { oligosaccharides as prebiotics }\end{array}$ \\
\hline Prickly pear & Opuntia ficus-indica & Cactaceae & Ascorbic acid, vitamin E, tocopherol \\
\hline Muskmelon & Cucumis melo L. & Cucurbitaceae & Caffeic acid, ferulic acid, minerals (B, Ca, K, Se, Zn) \\
\hline Watermelon & Citrullus lanatus & Cucurbitaceae & Vitamin $\mathrm{C}$, L-citrulline, minerals $(\mathrm{Mg}, \mathrm{Ca}, \mathrm{Zn}, \mathrm{Cu}, \mathrm{K})$ \\
\hline Apple & Malus domestica & Rosaceae & $\begin{array}{l}\text { Vitamin A, vitamin } \mathrm{C} \text {, short chain fatty acids as } \\
\text { prebiotic, phytosterols }\end{array}$ \\
\hline Pear & Pyrus communis $L$. & Rosaceae & Vitamin $\mathrm{C}$, zinc, iron, chlorogenic acid \\
\hline Apricot & Prunus armeniaca $\mathrm{L}$. & Rosaceae & Carotenoids, ascorbic acid, flavonoids, zinc \\
\hline Orange & Citrus sinensis & Rutaceae & Vitamin $\mathrm{C}$, vitamin $\mathrm{E}$ \\
\hline Citron & Citrus medica & Rutaceae & Carotenoids, ascorbic acid, phenolic acid \\
\hline Lemon & Citrus limon & Rutaceae & Carotenoids, ascorbic acid, zinc \\
\hline Strawberry & Fragaria ananassa & Rosaceae & Vitamin C, ellagic acid, procyanidins \\
\hline Blueberry & Vaccinium corymbosum & Ericaceae & Flavanoids, polyphenols \\
\hline Cranberry & Vaccinium macrocarpon & Ericaceae & Vitamin C, vitamin E, ellagic acid, anthocyanins \\
\hline Blackberry & Rubus fruticosus & Rosaceae & Carotenoids, anthocyanins, iron \\
\hline
\end{tabular}

The non-flavonoid compounds comprise of resveratrol, gallic acid, ellagic acid, chlorogenic acid, ferulic acid, caffeic acid and coumaric acid. Resveratrol is mainly found in grapes, cranberries and blueberries. It reduces the body fat and regulates obesity. The concentration of good bacteria such as (Lactobacillus and Bifidobacterium) increases and improves the gut microbiota (Brown et al., 2015). Chlorogenic acids are found in apples, berries and grapes. They reduce the inflammation process. Ferulic acid also acts an anti-inflammatory agent by reducing the activity of NFkB (Hole et al., 2012). Coumaric acid and caffeic acid shows high antioxidant capacity. Gallic acid and ellagic acids are found in blackcurrants and berries, respectively; both showcasing antioxidant and anti-inflammatory activities. 


\subsection{Dates (Phoenix dactylifera $\mathbf{L}$.)}

Date palm fruit belongs to the family Palmae called as Arecaceae. It is a monocotyledonous species that is found mostly in arid and semi-arid regions (El Hadrami and Al-Khayri, 2012). The date palm trees take up to 8 years to bear fruits that are about 3 to $7 \mathrm{~cm}$ in length and 2 to $3 \mathrm{~cm}$ in width. Most of the fruits contain stone inside. The colour of the fruit varies from red to brown during various ripening stages. The four ripening stages are kimiri, balah, rutab and tamar (unripe to fully ripen stage, respectively). Dates are rich in fibre content that varies depending on the types, ripening stages and the climatic conditions (Elleuch et al., 2008).

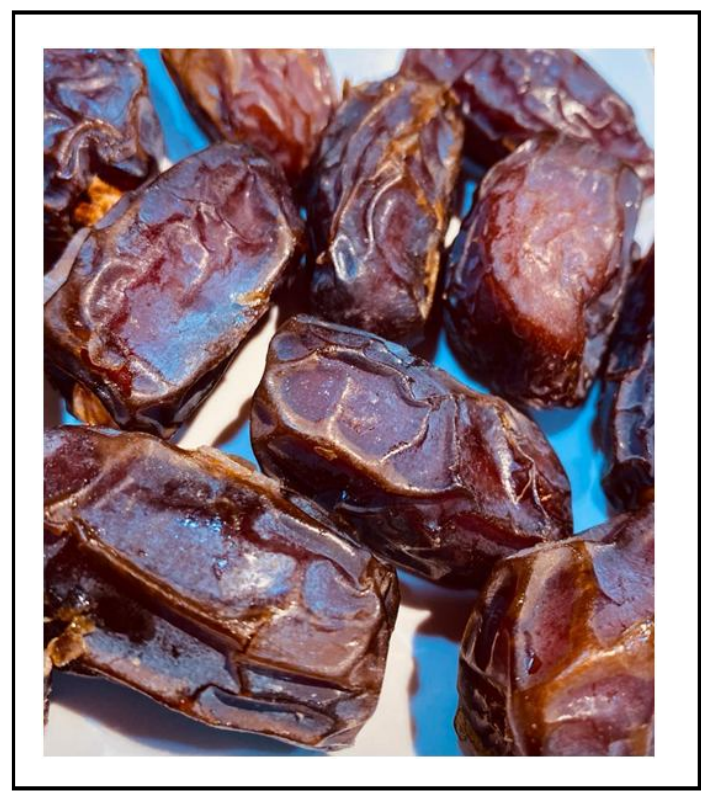

Dates

Fibres are highest in kimir stage $(250 \mathrm{~g} / \mathrm{kg})$ and decreases drastically as it proceeded to tamar stage $(50 \mathrm{~g} / \mathrm{kg})$. This is due to the fact that as they ripe, the fibres are enzymatically converted to soluble components that produce fresh and tender date fruit. On average, the fibre content ranges from 8-13 g/100 $\mathrm{g}$ in fresh fruits and 18-30 $\mathrm{g} / 100 \mathrm{~g}$ in dried fruits. Apart from high dietary fibre, dates also contain high carbohydrate in the form of sugar content (sucrose, glucose and fructose). The sugar content in fresh fruits are less than in dry fruits as the drying process reduces the water activity, thereby increasing the sugar content (Myhara et al., 1999). Unlike fibres and sugar, date fruits possess very less protein and lipid content. The protein content in fresh and dry dates is 1.50 and 2.14 $\mathrm{g} / 100 \mathrm{~g}$. These proteins account for non-oxidative browning reactions. A variety of amino acids are present in these fruits such as aspartic acid, proline, glycine, histidine, valine, leucine and arginie, unlike theronine, serine, methionine, isoleucine, tyrosine, phenylalnine, lysine, and alanine (Assirey, 2015). These fruits also possess a range of saturated fatty acids (capric, lauric, myristic, palmitic, stearic, etc.) and unsaturated fatty acids (palmitoleic, oleic, linoleic, and linolenic acid). These acids improve the organoleptic properties of the fruit. Minerals such as iron, zinc, manganese, potassium, calcium, phosphorous, etc., are found in abundance in this fruit. Studies done in Indian variety of dates showed that potassium was found the maximum $(713-894 \mathrm{mg} / 100 \mathrm{~g})$, followed by calcium (70.33-195.33 mg/100 g), magnesium (53.33-58.33 mg/ $100 \mathrm{gm}$ ) and phosphorous (15-52.66 mg/100 gm) (Vinita and Punia, 2016). Iron ranged from 4-6 mg/100 gm. Vitamin B-complex, C, K and $\mathrm{A}$ are found in dates. The vitamin content is higher in fresh fruits rather than dried dates. These vitamins are very important in regulating the proper functioning of liver and kidney (Vayalil, 2012).

Tannins, plant polyphenols give the astringent taste to the fruit. Its contents decrease as the ripening proceeds. Phenolic acids, a secondary plant metabolite is rich in date fruit. Their content increases from $193.7 \mathrm{mg} / 100 \mathrm{~g}$ in fresh fruit to $239.5 \mathrm{mg} / 100 \mathrm{~g}$ in dried fruits as the tannins are degraded and the enzymes are activated during drying process at high temperatures. Korkobbi date variety has the highest phenolic content whereas the Tunisian date variety has the least content (Chaira et al., 2009). Carotenoids are fatsoluble pigments that provide colour to the fruit. They are an important source of vitamin A which possess radical scavenging ability, and thus acts as an antioxidant. Their concentration is lower in dried fruits. Carotene rich date fruits protect the human body from chronic ailments. Anthocyanins, a flavonoid, are also present in the fruit that give colour to the fruit (Al-Farsi et al., 2005). All these phytochemicals possess antioxidant properties by inhibiting the protein oxidation, peroxidation, LDL and VLDL oxidation (Vayalil, 2002). Apart from radical scavenging, they also possess medicinal attributes like hepatoprotective capacity, nephrotoxic protection, and neuroprotective ability. Dates possess low glycaemic index (GI). In spite of having rich sugar content, the synergetic effect of minerals and vitamins provide the glucose balance in controlling diabetes. The rich dietary fibre content enhances insulin sensitivity and other gut hormones (Weickert and Pfeiffer, 2008). Hypercholesterolemia and hypertension are controlled due to the mineral concentration $(\mathrm{Mg}, \mathrm{Ca}, \mathrm{Na}, \mathrm{K})$ through renin-angiotensin system.

\subsection{Olive (Olea europaea L.)}

Olive fruit belongs to the family Oleaceae which is found mostly in tropical and sub-tropical regions. The fruit measures about $2.5 \mathrm{~cm}$ approximately with a stone inside also called as pit. Olive fruits are composed of water $(50 \%)$, protein $(1.6 \%)$, oil $(22 \%)$, carbohydrate $(19.1 \%)$, cellulose $(5.8 \%)$, inorganic substances $(1.5 \%)$, and phenolic compounds (1\%-3\%) (Anagnostopoulou et al., 2006). Along with these nutritional compounds are found certain bioactive components like phytosterols, tocopherols and triterpenoids that are nonphenolic compounds and phenolic acids, phenolic alcohols and flavonoids that are phenolic compounds.

The tocopherols are a source of vitamin E that acts as natural antioxidants by defending the body against free radical attack. It protects the body against various cancers. The triterpenoids found in olive fruit are maslinic acid and oleanolic acid which mainly account for antidiabetic activity along with anti-inflammatory and anticancer activities (Mullauer et al., 2010). These acids exhibit good insulin secretion and response by reducing postprandial hyperglycaemia (Castellano et al., 2013). These triterpenoids also exert antitumour activity by apoptosis, cell proliferation, etc., on breast cells. Anti-inflammatory effect is shown by inhibiting the NO production and TNF- $\alpha$ (Huang et al., 2011). These fruits also have other phenolic compounds like oleuropein that exhibits antitumour, anti-inflammatory, antidiabetic and antioxidant activities 
in large scale. These biological effects improve the human health (Bulotta et al., 2014).

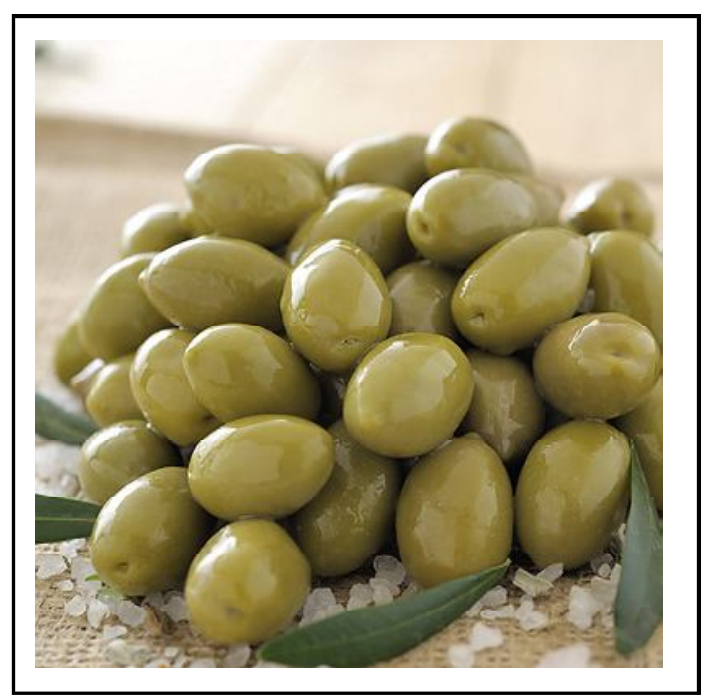

Olives

\subsection{Passion fruit (Passiflora edulis Sims)}

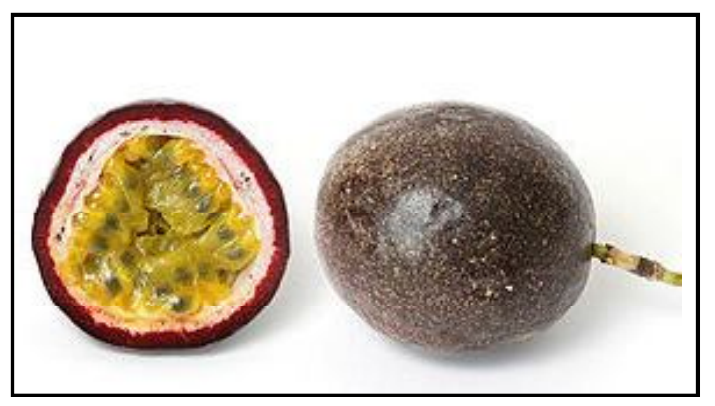

Passion fruit

The passion fruit belongs to the family Passifloraceae that has around 600 species of fruits and flowers together found mostly in tropical and sub-tropical regions. The fruits are found in different colours like purple, orange and yellow depending on the maturing stages which grows up to $4-10 \mathrm{~cm}$ in length (López-Vargas et al., 2013). These fruits are rich in vitamins, especially $A$ and $C$, minerals and other bioactive components like flavonoids, anthocyanin, phenolic acids, tocopherols, etc. All these compounds beneficially account as health promoting activities like management of diabetes, glucose levels and insulin levels and in the gut microbiota. Also, some of them act as good antioxidant and anticancer agents. Some of the important flavonoids that exert health benefits are apigenin3-rhamnoside, luteolin-3-glucoside, quercetin and kampferol. Another polyphenolic compound called piceatannol is a strong antioxidant and also reduces the proliferation of cancer cells showing strong anticancer properties (Piotrowska et al., 2012). Passion fruit contain wide range of vitamins in which ascorbic acid, a watersoluble vitamin is found in abundance. This acts as good antioxidant contributing to a healthy immune system (Janzantti et al., 2012). Carotenoid, a form of vitamin A is also found in this fruit. It is made of lycopene, carotenes, etc., that provide colour to the fruit
(Strati et al., 2012). Many researchers suggest that moderate consumption of passion fruit acts on LDL cholesterol and decreases the risk of many cardio vascular disorders (Kendall and Ryan, 2009).

De Souza et al. (2012) studied that fruit juices of passion fruit improved the HDL and decreased the LDL; thereby controlling the lipid profile. Similarly, Marques et al. (2016) experimented with passion fruit peel flour in the diet of HIV patients. Same effects were obtained proving the capacity of the fruit to perform as reducing agent of hyperlipidaemia and hypercholesterolemia. Anusooriya et al. (2014) suggested that aqueous extract of passion fruit reduced blood glucose levels. Some studies also reveal that insulin-positive cells were positively developed due to the consumption of these fruit, providing antidiabetic activity. Anti-inflammatory activity is required to avoid long-term over-inflammations that might cause disorders in body like rheumatic arthritis. This is found by different activities like leucocyte migration, inhibition of interleukin-8 (IL-8) and matrix metalloproteinase (MMP-1) (Montanher et al., 2007). All these actions are taken care mostly by the flavonoids found in the fruit (Flores et al., 2012).

\subsection{Persimmon (Diospyros kaki L.)}

Persimmons are a type of fruit that belong to the family Ebanaceae that roots to Asia, specifically China. It grows as a tree up to 10-16 meter in length. This fruit is low in protein and fat. Carbohydrates are mainly composed of sugar (glucose, sucrose and fructose). Other micronutrients like vitamins (A and $\mathrm{C}$ ) and minerals are found in the fruit (magnesium, potassium and phosphorus). Ascorbic acid acts as a good anti-oxidant by limiting the free-radicals. The amount of vitamin $\mathrm{C}$ and vitamin $\mathrm{A}$ in one fruit satisfies about $46 \%$ and $31 \%$ of the daily requirements (Rao and Rao, 2007). Vitamin A in the form of carotenoids gives the fruit its colour along with providing certain medical benefits like reducing degenerative diseases and cancer (Abuajah et al., 2015).

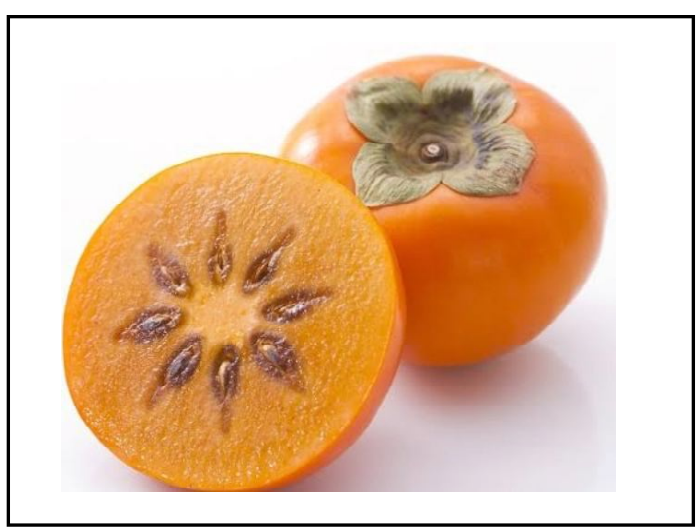

Persimmon fruits

Tannins are found in greater quantity in this fruit which provides its astringent property. Tannins are mainly composed of catechin (epicatechin gallate, epigallocatechin gallate, epigallocatechin) that provides the antioxidant, antimicrobial, antiviral, anticarcinogenic capacity. Persimmons also provide positive effect against CVD, urinary tract disorders, etc. (Abuajah et al., 2015). The phenolic acid present in the fruit exerts the following activities; antioxidants exhibit potential antifungal, antibacterial, anti-inflammatory, and 
anticancer (Gu et al., 2008). The high fibre content in persimmons reduces the appetite, thereby blocking the glucose in the intestine. This technique reduces the blood sugar level and the cholesterol level, aiding in maintaining the sugar level and the lipid profile (Gorinstein et al., 2011). High antioxidant content present in persimmon fruit traps the LDL oxidation which obesity and CVD. 24-hydroxyursolic acid, a triterpenoid found in this fruit inhibit the growth of cancer cells (Khanal et al., 2010).

\subsection{Pineapple (Ananas comosus L.)}

Pineapples are a native to South America that grows well on tropical and sub-tropical regions. There are many varieties of the pineapple based on their shape, size, etc. Pineapples are made up of carbohydrates as a form of dietary fibre and sugar, along with a wide source of vitamins (A, B, C) and minerals ( $\mathrm{Ca}, \mathrm{Fe}, \mathrm{P})$.

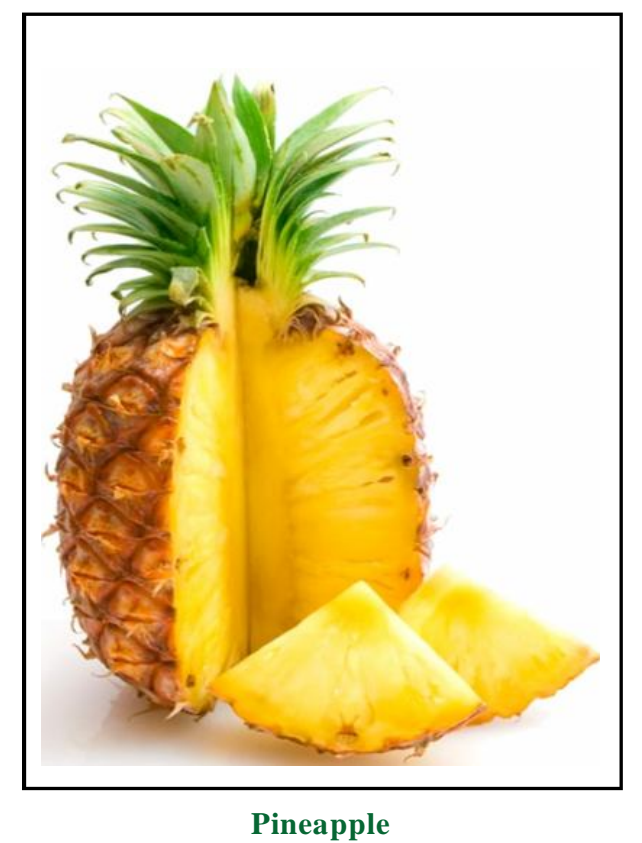

The antioxidant activity was exerted due to the presence of carotenes and ascorbic acids in the fruit that varies depending on the maturation stages. Studies by Zdrojewicz et al. (2018) suggest that one ripe pineapple satisfies about $16 \%$ of recommended dietary allowance of vitamin C. Thiamine quantity in pineapple looks after the nervous system in human body. Also, manganese present in the fruit satisfies about $73 \%$ of RDA. This mineral is very important for maintaining blood glucose level and insulin secretion (Zdrojewicz et al., 2018). Similarly, fibre content is rich in this fruit (69.1-81.5 $\mathrm{g} / 100 \mathrm{~g}$ ) that it regulates proper bowel movement and limits the risk of CVD, diabetes and colon cancer (Dittakan, et al., 2018). Phenolic acids and flavonoids are present in huge quantities in pineapples that give the radical scavenging property to the fruit making it a strong antioxidant.

Antioxidant activity is also found due to other components like flavonoids, isoflavones, flavones, anthocyanin, catechins and phenolic acid. Other compounds found in their ripe stage are esters, terpenes, terpenoids, alcohols, phenols, and aldehydes (Adiani et al., 2020). These compounds have a positive effect against microbes. Pineapple is a source of natural proteolytic enzyme called bromelain that shows some therapeutic activities like antioxidant, anticancer, anti-inflammatory activities (Zdrojewicz et al., 2018). Hence, the fruit can also be replaced for proteolytic enzyme for soft tissues. This compound also exerts other vital health benefits to treat bronchitis, pneumonia, gastrointestinal infections and mainly protection against bacterial and parasites infections. Malic acid present in pineapples enhance the human body immune system.

\subsection{Papaya (Carica papaya L.)}

Papaya belongs to the family Caricaceae that grows extensively in tropical and sub-tropical regions. The papaya tree is a native of Central America. The whole plant is used for different purposes by people of different regions. As a whole, medicinal benefits are exerted from the roots, stems, leaves, seeds, and ripe and unripe fruits (Pandey et al., 2016). Seeds form up to 6-8\% of the fruit which is made of proteins $(27.8 \%)$, lipids $(28.3 \%)$, crude fibre $(22.6 \%)$, sucrose $(75 \%)$, etc. They also have a variety of bioactive compounds like alkaloids, glucosinolates, isothiocyanate, phenolic acids, and flavonoids (Gogna et al., 2015). These are used for many healthrelated treatments like diabetes, hypercholesterolemia and hypertension. Leaves of the papaya plant consist of biocompounds like flavonoids, saponins, tannins, phenolics, alkaloids, etc.

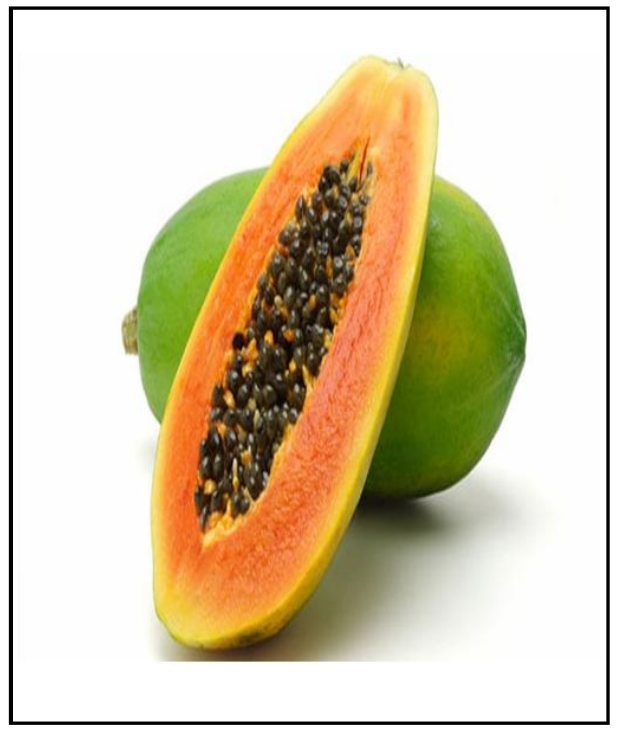

Papaya fruit

These aid in the treatment of diabetes and a few STD's like gonorrhoea, syphilis, etc. (Ezikanyi et al., 2016). Anti-inflammatory effect is seen both in seeds and leaves (Owoyele et al., 2008). Anticancer effects against of stomach cancer, lung cancer, pancreatic cancer, colon cancer, and leukaemia are observed (Pandey et al., 2017). Extracts of papaya leaves increase the immune responses by stimulating the production of cytokine and aids in betterment of human health (Otsuki et al., 2010). Papaya fruits vary in colour from green to yellow depending on the ripening stage. It is consumed without seeds. The ripe fruit is a rich source of alkaloids, phenolic acids, flavonoids, saponins, tannins, carotenoids, vitamins like A, $\mathrm{B}$ and $\mathrm{C}$ and minerals along with dietary fibre. Saponins, cardenolides and folic acid in the fruit prevent CVD (Oloyede, 2005). Papain component present in papaya is associated with antimicrobial, anthelmintic, antimalarial, antifungal in human. Papain 
also breaks down the fibrin present in cancerous cells, thus proving to be an anticancer agent. Pandey et al. (2016) exclaimed that papaya fruit also has secondary metabolites that showed immunomodulatory and anti-inflammatory effects. Papain with other proteolytic enzymes like trypsin and chymotrypsin decreases the TGF $\beta 1$ concentrations, and thereby treating rheumatoid arthritis. Ripe papaya fruit increases IgM level that enhances the humoral immunity (Sadek, 2012). The phenolic compounds present in papaya show antioxidant properties. It also maintains health of the gastrointestinal tract by keeping a good gut microbiota. The carotenoid present in the fruit is responsible to prevent degenerative diseases like cancer (Rivera-Pastrana et al., 2010). Fermentable pineapple products improved the antioxidant defence immune mechanism in elder patients that lacked basic antioxidant state. They offer protection on leucocytes enhancing the immune responses (Marotta et al., 2006). Many countries use pineapple extract to treat malaria, dengue and other fungal infections. The leaf extract has been used to increase the blood pallet count (Dharmarathna et al., 2013). Apart from the above said medicinal properties, they also possess immune stimulating and antioxidant capacity that enhances immunity.

\subsection{Dragon fruit (Selenicereus undatus (Haworth) D.R. Hunt)}

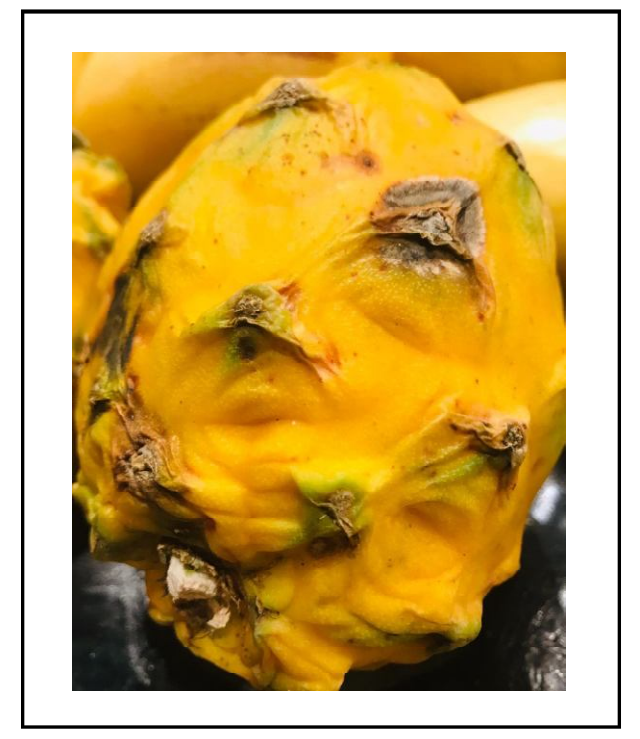

Dragon fruit

Dragon fruit originates from Mexico and Central America belonging to the Cactaceae family. This fruit is rich in fibre and carbohydrates in the form of sugar (glucose, fructose and sorbitol). A wide range of vitamins (A, B, C) and minerals ( $\mathrm{Ca}, \mathrm{Fe}, \mathrm{Mg}, \mathrm{P}, \mathrm{K}, \mathrm{Na}, \mathrm{Zn})$ are present in the fruit (Jaafar et al., 2009). Flavonoids found in the fruit prevent CVD. Polyphenols in the fruit exerts the antioxidant activity on obesity disorders (Song et al., 2016). The fibre content helps in regulation the bowel movement and easy digestion. This helps in controlling the glucose level. The vitamin B complex act as a multivitamin and regulates the cholesterol levels. The high quantities of vitamin $\mathrm{C}$ act as good antioxidant and enhance the immune system. Dragon fruits possess high levels of oligosaccharides $(8.60 \%-50.01 \%)$ that behaves as prebiotic component. These prebiotics have a positive correlation with boosting the functioning of immune system (Kazemi et al., 2019). These prebiotics promote the growth of probiotics, beneficial gut bacteria that prove to be beneficial in regulating the immune system (Zhang et al., 2018). Research on understanding the effect of oligosaccharides as a prebiotic source to improve the immune health of rats was done with dragon fruit powder which was formed by spray-drying technique. The results show that there was increase in the good bacteria (bifidobacteria and lactobacilli) and decrease in the bad bacteria (bacteroides and clostridia). Similarly, the immunoglobulin levels were recorded. There was significant increase in the same. The plasma of rats fed with the fruit powder had increased levels of $\operatorname{IgA}(7.273+/-3.681$ times) and $\operatorname{IgG}$ levels (16.207+/- 11.133 times). Thus, the prebiotic effect of in vitro consumption of dragon fruit has successfully established positive immune response (Campos et al., 2012).

\subsection{Prickly pear (Opuntia ficus-indica (N.L.) Mill.)}

The prickly pear belongs to Cactaceae family that has its native at Mexico which grows well in arid and semi-arid regions. The fruit is usually eaten with its seeds. This fruit is rich in fibre content that it prevents cancer, diabetes and thus obesity. The fruit pulp is rich in minerals like potassium and magnesium while the seeds were greater in calcium. This fruit is rich in vitamin $\mathrm{E}$ and vitamin $\mathrm{C}$. The concentration varies according to types and harvesting parameters. Valente et al. (2011) found that prickly pear had 10 times more ascorbic acid than dragon fruit. Also, the fruit peels had double the vitamin $\mathrm{C}$ than the fruit pulp. Vitamin $\mathrm{E}$ is found in the form of tocopherols. Bioactive compounds like phytosterol, phenolics, flavonoids, etc., are also found. The phytosterols control the lipid profile and plasma cholesterol, thereby regulating CVD (Ostlund, 2002).

Carotenoids in the form of carotenes, lutein, etc., are found in prickly pear that also prevents CVD along with a few cancers. These compounds provide colour to the fruit. Polyphenols offer antiinflammatory, antiproliferative activity and antiallergenic activity (Costa et al., 2015). 60\% of the fatty acids present in this fruit are unsaturated, thus providing good cholesterol content to the body by controlling the lipid profile. The combined effect of the compounds provides different protective effects like antioxidant, anti-inflammatory, antiproliferative activities. The antioxidant capacity in the prickly pear fruit is greater than many other fruits grapefruit, orange, apples, etc. (Butera et al., 2002). This high activity is devoted to the presence of compounds like vitamin $\mathrm{C}$, carotenoids, quercetin and kaempferol. Polyphenols provide the anti-inflammatory effect. The extracts of prickly pear reduced the production of COX2, TNF- $\alpha$, and IL- 6 . They also inhibited the NO synthesis, thereby reducing the secretion of cytokine (AntunesRicardo et al., 2015). The antiproliferative effect inhibits the cancer cell formation. This activity is attributed to the flavonoids in the fruit, especially indicaxanthin. This compound also shows immunomodulatory effects (Tesoriere et al., 2004). Other compounds like isorhamnetin diglycosides, ferrulic acid and betacyanins inhibit cell proliferation colorectal cancer cells showcasing their antiproliferative activity (Serra et al., 2013). Other polyphenols present in prickly pear reduces the risk of diabetes and CVD. 
3.9 Muskmelon (Cucumis melo L.)

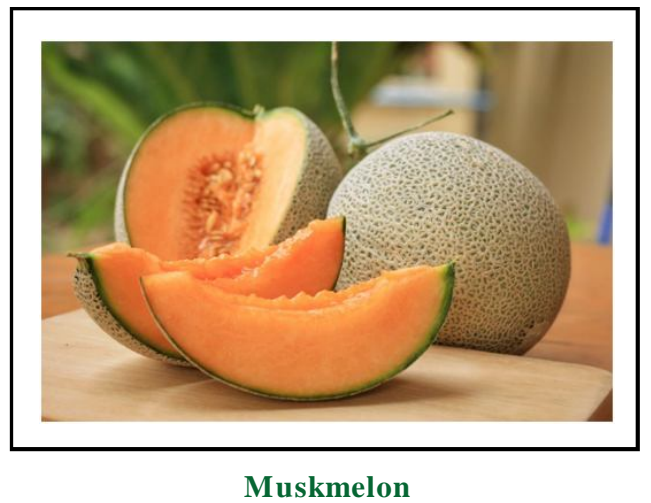

Muskmelon belongs to Cucurbitaceae family which originates back to East Africa. They vary in shapes from oval to elongated and colour from white to magenta. This fruit is composed of $905-97 \%$ of water that act as a good hydrating fruit. They also contain carbohydrate, fibre and protein content; low in fat and cholesterol. Vitamins and minerals provide enough health properties to the fruit (Lester, 1997). Muskmelons possess anti-inflammatory, analgesic and antioxidant capacity (Arora et al., 2011). These activities attribute to secondary metabolites. The carbohydrates are in the form of sugar (mono-and-di) and starch. Although, the fat content is very minimal, the available fatty acids are omega- 3 and omega- 6 which are good fatty acids. Vitamin A is in the form of carotenoids, carotenes, lutein, etc. The vitamin B-complex prevents macular degeneration. The ascorbic acid is very rich in muskmelon that acts as antioxidant. $100 \mathrm{~g}$ of the fruit has $40 \mathrm{mg}$ of ascorbic acid. Vitamin $\mathrm{K}$ in the fruit prevents CVD and regulates blood clotting. The fruit has minerals sources like calcium, magnesium, zinc and selenium that are important for better immune system functioning and improved defence mechanism in human body. The antioxidant capacity of muskmelon is attributed to the presence of compounds like ascorbic acid, carotenoids, tocopherols, phenolic acids and flavonoids. These compounds present in various parts of the fruit like peel, pulp, seeds, etc., all aid in radical scavenging (Mehra et $a l ., 2015)$. Luteolin is a flavonoid that disrupts the cancerous cell growth and reduces the risk of a few cancers like breast, lung and colon (Yang et al., 2014). Caffeic acid and ferulic acid possess antioxidant capacity, antiproliferative effect and antimicrobial, antiinflammatory and antioxidant activities, respectively (Prasad et al., 2011). Highly nutritious muskmelon fruit has many health benefits that helps keep the body in a good state.

3.10 Water melon (Citrullus lanatus (Thunb.) Matsum. \& Nakai)

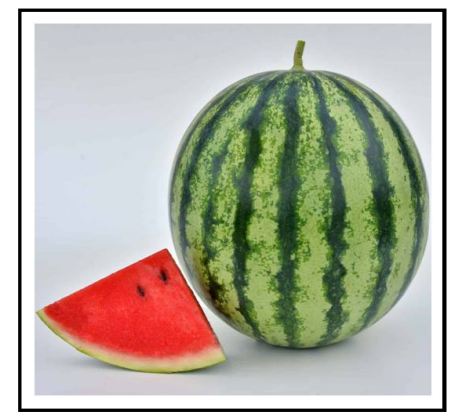

Watermelon
Watermelons belong to Cucurbitaceae family that has its native at Africa. It is one of the most consumed fruit all over the world. This fruit varies in shape, size, colour and rind patterns. Water melons are composed of $90-95 \%$ water. Apart from this, they also possess sugars, vitamins and minerals. The sugar component is made of glucose, fructose and sucrose; with fructose dominating that provides the sweetness to the fruit (Candir et al., 2013). Vitamins A and C are the main vitamins present in the fruit. These vitamins perform many biological functions like collagen synthesis and neurotransmission. They are also very important in immune system functioning. Vitamin Ain the form of carotenoid acts as antioxidants. A range of minerals like magnesium, calcium, zinc, copper, potassium, etc., are present in water melon. These minerals aids in different functioning of the body parts along with stimulating immune responses. Apart from the nutritional composition, certain bioactive compounds give the fruit good health benefits. Lycopene and carotenoid in this fruit act as radical scavenging components; thereby enhancing its antioxidant capacity (Kim et al., 2014). Lycopene also aids in prevention of chronic ailments like cancer, hypercholesterolemia, diabetes, etc. (Naz et al., 2014). The polyphenols and the flavonoids prevent biological disorders like diabetes and CVD. Consumption of this fruit reduces the bad cholesterol LDL; thereby maintaining the lipid profile. Altas et al., (2011) exclaimed that watermelon juice protects the kidney, liver and brain from carbon tetrachloride toxicity. Watermelon is very important in proper functioning of the immune system because of the presence of an aminoacid known as L-citrulline. This acts as an effective precursor of L-arginine that gets oxidised to nitric oxide; which is an essential component in modulation of proper immune responses (Wu et al., 2007).

\subsection{Apples (Malus domestica Borkh.)}

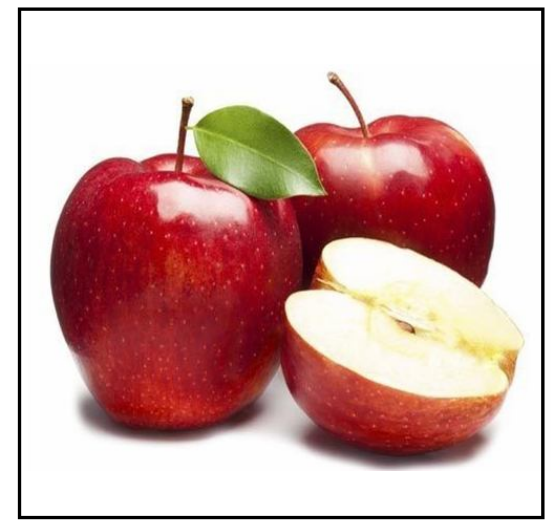

Apples

Apples belong to the family Rosacea whose native is Central Asia. It is one of the most consumed fruit (20-30 kg/ capita per year) all over the world with various kinds of varieties like Gala, Topaz, Golden delicious, Granny smith, etc. It is grown well in temperate to sub-tropical regions. Due to the health attributes, the fruit has gained itself a proverb, "An apple a day keeps the doctor away". This is due to the fact that it is rich in sugar and other essential micronutrients and phytochemicals. The energy gained by consuming 100 grams of apple is $55 \mathrm{kcal}$ which is in the form of carbohydrates as sugar (glucose, fructose and sucrose). Apples are low in fibre, protein content and lipids. Vitamin B-complex (300 $\mu \mathrm{g} / 100 \mathrm{~g})$, vitamin C (10 mg/100 g), vitamin E (0.5 mg/100 g) are 
relatively high in apples that attribute to its high antioxidant activity ( $\operatorname{Rad}$ et al., 2014). The fermentable fibres produce short chain fatty acids to act as prebiotic sources that improve the gut microbiota; thereby enhancing the immune health. Phytonutrients like flavonoids, polyphenols and triterpenes are rich in apples. These are mainly found on the peels than the pulp. Thus, peeling the apples before consumption significantly reduces $25 \%$ of the phenolic acid (Kevers et al., 2011), 40\% of ascorbic acid (Lata and Tomala, 2007) and 50\% of fibre (Leontowicz et al., 2007). Thus, the best way to consume an apple is without peeling it while it is grown organically, that does not hamper the components of the peels. These phenolic acids act as radical scavengers and also alter few gene expressions that improve the anti-inflammatory activity and boost the body's own antioxidant action. Triterpenes exhibit antiproliferative and anti-inflammatory actions (Mueller et al., 2013). Phytosterols lower serum cholesterols and also improve functioning of immune system in body (Worbs $e t$ al., 2017). Studies show that apple consumption reduces the blood pressure due to the availability of potassium (Oude Griep et al., 2013). Other studies found that combined consumption of apples with pears provide greater synergetic benefits like higher antioxidant capacity, reduced risk of stroke, reduced risk of diabetes, reduced risk of cancers, etc. (Wedick et al., 2012). Overall, apples offer many health benefits like protection against chronic ailments-CVD, T2DM, cancer, etc., and all these indirectly contribute to a healthier immune system.

\subsection{Pears fruits (Pyrus L.)}

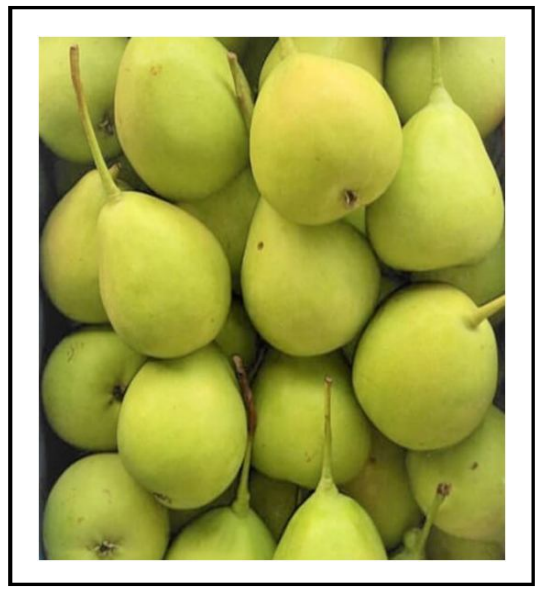

Pears

Pears belong to the family Rosaceae whose native is Middle East and subalpine regions. The most important genus is Pyrus genus with various subspecies. It is a seasonal fruit that is consumed for its high health benefits apart from juicy and tasty attributes. It varies in shapes, size and colours. It is composed of carbohydrates in the form of sugar (glucose, fructose, sorbitol and sucrose); that aid in the treatment of diarrhoea (Reiland and Slavin, 2015). Fibre in the fruit eases digestion but also improve the gut health. The fatty acids present in the fruit increases the absorption of trace elements that helps the body improve the general health by enhancing disease resistance capability (Sha et al., 2011), which is the need of the hour to fight against any viral attack. A range of minerals found in pears contribute to different health ailments. Potassium ensures salt balance while calcium and magnesium protect bones. Iron is important for circulatory system. Zinc plays a vital role in the immune health. The peel of the fruit consists of flavanols and hydroxycinnamic acid while the pulp consists only of the hydroxycinnamic acid (Fattouch et al., 2008). Polyphenols and phenolic acid attributes to radical scavenging activity. Chlorogenic acid found in pears is known for its chemoprotective and antitumor capacities (Krakauer, 2002). They also possess immune strengthening properties.

\subsection{Apricot (Prunus armeniaca L.)}

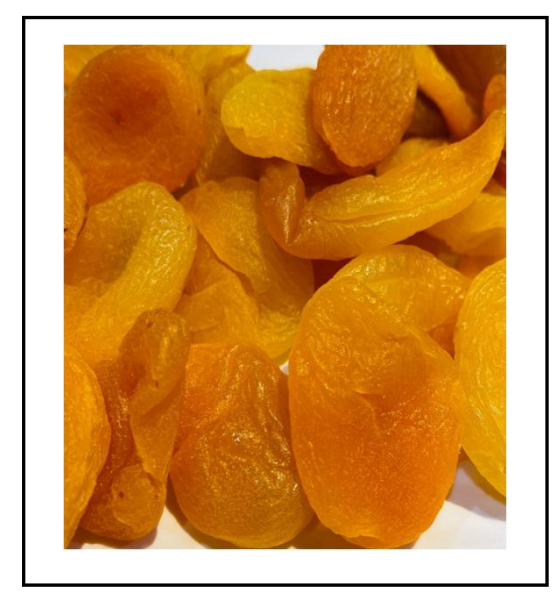

Apricot (Dried)

Apricots belong to Rosaceae family which originates from Chinese regions that grows well in temperate regions. These fruits are grown over 3000 years for its health benefits. Though, it is a watery fruit with $86.35 \%$ of water constituent, it is also consumed as a canned and dried fruit. The protein content of the dried apricot $(3.39 \mathrm{~g} / 100$ $\mathrm{g})$ is much more than that of the fresh fruit $(1.40 / 100 \mathrm{~g})$. Sugars present in this fruit are glucose, sucrose and fructose with sucrose dominating others. Apricots are rich in minerals like calcium (13 $\mathrm{mg} / 100 \mathrm{~g})$, iron $(0.39 \mathrm{mg} / 100 \mathrm{~g})$, magnesium $(10 \mathrm{mg} / 100 \mathrm{~g})$, manganese $(0.077 \mathrm{mg} / 100 \mathrm{~g})$, zinc $(0.20 \mathrm{mg} / 100 \mathrm{~g})$ selenium $(0.1 \mu \mathrm{g} / 100 \mathrm{~g})$, etc. Vitamins A, B complex, C, E and $\mathrm{K}$ are found in these fruits. Tocopherols, carotenoids and ascorbic acid content enhance the antioxidant capacity of the plant (Sass-Kiss et al., 2005). A range of polyphenols including chlorogenic acid, and quercetin-3rutinoside alleviates chronic ailments like cancer, diabetes and CVD (Dragovic-Uzelac et al., 2007). The activity of antioxidant from the extract of apricots are as follows descending order of sulphur dioxide-treated sun-dried $>$ sun-dried $>$ fresh (Güçlü et al., 2006). Oomah and Mazza (2000) reported many health benefits like treating CVD, cancers, etc. Melanoidins, a phytochemical in apricot protects mitochondrial damage and cell apoptosis; thereby preventing CVD (Cossu et al., 2012). The apricot kernel oil is used in the treatment of myocardial infarcts (Zhang et al., 2011). This oil also lowers the cholesterol level and maintains the lipid profile in control; thus, used in the treatment of hypercholesterolemia. By supressing the NO synthesis, anti-inflammatory action is showcased by the consumption of apricots. The methanol extracts of apricot bitter kernels showed antimicrobial activities against Gram-negative bacteria Escherichia coli. Similarly, aqueous bitter extracts showed antimicrobial effects against Gram-positive bacteria Staphylococcus aureus (Tian et al., 2011). 


\subsection{Citrus fruits (Citrus L.)}

Citrus fruits belong to Rutaceae family and is one of the most important crops in the world both for production and economic value grown mostly in tropical and subtropical regions. They vary according to different sizes and shapes. They have juicy pulp under a peel. These fruits are consumed as such or as juices. The citrus genus is very varied with categories as follows: "sweet oranges $(C$. sinensis), mandarins (C. unshi), tangerines (C. tangerina, and $C$. reticulata), and clementines (C. clementine), sour/bitter oranges $(C$. aurantium), lemons (C. limon), limes (C. aurantifolia and $C$. latifolia), grapefruit (C. paradisi) and pummelos (C. grandis), hybrids (e.g., tangelos, tangors, and limequats), and citrons ( $C$. Medica)" (Ortiz, 2002). There are many beneficial compounds found in this fruit including fibre, vitamins $(\mathrm{A}, \mathrm{B}, \mathrm{C})$ and minerals $(\mathrm{P}, \mathrm{Mg}$, $\mathrm{Cu}$ ) and other phytochemicals (Gonzalez-Molina et al., 2010).

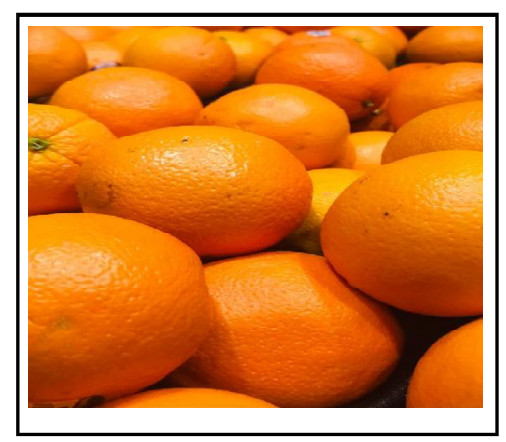

Oranges

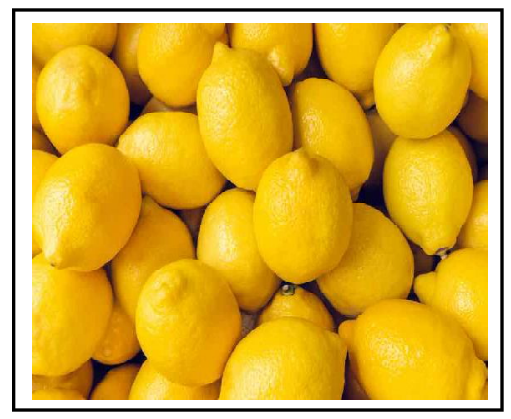

Lemons

Carotenoids, limonoids, alkaloids, flavanoids and phenolic acids are present in the citrus fruits that exert medicinal benefits like antioxidant property, protection against CVD and enhancing the immune health. The quantity of these phytochemicals vary according to maturation and storage conditions of different variety of the fruits (Vikram et al.,2015). Citrus fruits are known for its vitamin $\mathrm{C}$ content, a water-soluble vitamin. Consumption of these fruits satisfies $100 \%$ of the vitamin C RDA. Studies suggest that $200 \mathrm{mg} /$ day of vitamin C offers various health benefits (Frei, 2012). This compound is highly essential for human health as they act as an excellent source of antioxidant. $40-55 \%$ of the antioxidant potential comes from ascorbic acid of oranges, mandarins and grapefruit (Szeto et al., 2002). They improve the immune health by stimulating WBC functioning. Ascorbic acid reduces the severity of cold (Wintergerst et al., 2006). Vitamin C is also involved in iron metabolism, acts as neurotransmitter and as a co-factor in many enzymatic reactions (Palacios, 2006). Carotenoids (lutein, lycopene, terpenes, etc., are found extensively in citrus fruits. Especially Tangerines contain more pro-vitamin A and carotenoid that acts as a major source of vitamin A. $100 \mathrm{~g}$ of this fruit satisfies $72 \%$ vitamin A RDA (Arscott et al., 2010). Health benefits of vitamin A include improved eye health and bone functioning lowers CVD and cancer promoting properties (Nishino et al., 2009). Immune system has positive effects by the intake of vitamin A from citrus fruits (Katsuura, et al., 2009).

Fibres found in this fruit promote lactation and improves the feeling of satiety. Fibre consumption actively reduces blood glucose levels, cholesterol level and thus reduces the risk of CVD. This component also promotes healthy gut microbiota. Flavonoids and limonoids have anti-inflammatory properties (Habauzit et al., 2011). They also act as antiviral and antibacterial agents (Vikram et al., 2015). Phenolic acids mainly caffeic acid, ferulic acid and chlorogenic acid have high radical scavenging capacity. Gallic acid acts as a strong antioxidant (Karamac et al., 2005). The order of highest to lowest scavenging capacity of the phenolic acids are "gallic > gentisic > syringic $>$ caffeic $>$ protocatechuic $>$ sinapic $>$ ferulic $>$ isoferulic $>$ vanillic $>$ p-coumaric $>$ o-coumaric > m-coumaric > salicylic k" p-hydroxybenzoic" (Jabri Karou and Marzouk, 2013). The essential oils that contain geraniol and terpinolene extracted from the citrus fruits also exert antioxidant capabilities (Singh et al., 2010). Naringin, sudachitin and quercetin found in these fruits provide anti-inflammatory activities by inhibiting NO synthesis (Wang et al., 2011). The secondary metabolites found in citrus fruits like flavonoids, limonoids, and coumarins exert anticancer properties (Takuji et al., 2012). Poncirin showed inhibitory action against gastric cancer cells (Zhu et al., 2020) as quercetin and tangeretin affected the growth of cancer cells (Pan et al., 2002).All these evidences proves that citrus has antiviral activity too. Hesperidin is a flavone that shows promising chemopreventive properties. Citrox is a pharmaceutical formulation of various citrus flavonoids. This acts as antimicrobial formulations in oral hygiene (Hooper et al., 2010).

Oranges are filled with various phenolic compounds including flavonoids and flavones. Hesperidin and naringenin are rich in oranges. Hydroxycinnamic acid, caffeic acid, and ferulic acids are rich in oranges. Mandarin and their hybrids have various species flavones like hesperidin and naringin. Narirutin is another compound found extensively in mandarins. Lemons have huge quantities of flavone glycosides, while limes have hesperidin, eriocitrin, etc. Pummelo is one of the original varieties of the citrus genus. They are rich in narirutin, eriocitrin, naringin, and neohesperidin. Grapefruit is a hybrid of pummelo and sweet oranges. They are found in red and white (with lycopene/ without lycopene). The main constituent of this fruit is narirutin and naringin. Citron is the most primary species of this genus. They have hesperidin, eriocitrin and apigenin, the most abundant flavone in citron. Grape fruit consists of various elements that confer health benefits. The antioxidant capacity from vitamin $\mathrm{C}$, carotenoids and other polyphenols prevent CVD, cancer, etc. They also prevent infection and boost the immune system (Codoner-Franch and Valls-Belle's, 2010). Vitamin $C$ in the form of ascorbic acid and vitamin $A$ in the form of carotenoids also prevent cancer and CVD. They help in the absorption of $\mathrm{Fe}$ and $\mathrm{Zn}$. These elements help strengthening the immune system. Polyphenols, lycopene and flavonoids act as anti- 
inflammatory, anticarcinogenic, antiproliferative and antiviral agent. Coumarins and flavonoids in this grapefruit act as antimicrobial and antiviral agents (Vikram et al., 2015).

Studies showed that long term consumption of orange juice increased antioxidant levels and reduce the cholesterol levels (Constans et al., 2015). They have anti-inflammatory activity and anticarcinogenic activities. Vitamins C, B and A exerts medical benefits. Ascorbic acids regulate many bodily functioning like neurotransmission, collagen synthesis, etc. Citric, malic, succinic, tartaric, malonic, and oxalic acids are present in this fruit. Flavonoids and carotenoids present in oranges provide protection against CVD. They behave as anti-inflammatory agents, antitumor and antiviral agent (Yi et al., 2008). Lemons are a native of Asia which are grown in tropical, semitropical and regions of warm temperatures. These are highly acidic in nature. They possess huge quantities of vitamin $\mathrm{C}$, minerals and other polyphenols that confer health benefits. Ascorbic acid and B-complex vitamins become antioxidant responding compounds. Vitamin $\mathrm{C}$ maintains the lipid profile. The flavonoids in lemon act as anti-inflammatory, antitumour, antiproliferative and antimicrobial agent (Abeysinghe et al., 2007). Carotenoids reduce the risk of cancer and CVD. Terpenoids act as anti-inflammatory and antimalarial agent. They also prove to be anticarcinogenic agent (Poulose et al., 2005). The dried peels of lemon increases white blood cell count, and thereby improve the immune health.

\subsection{Berries}

Berries are one of the richest fruits in terms of natural compounds like fibre, vitamins, minerals and polyphenols. These compounds exert various health benefits and are used in disease prevention. These compounds provide a synergetic effect on human digestive system establishing a healthy gut microbiota. They protect the body against CVD, diabetes, obesity, cancer, etc. All this together improves the immune system of a person. They are also made up of rich phenolic acids like cinnamic acid, lignans, folates, alkaloids, carotenoids, etc., (Afrin et al., 2016). Berries are made of $15 \%$ of sugar along with fibre which makes it beneficial for diabetic people (Ramadan et al., 2008). Berries are composed with a range of vitamins like $\mathrm{A}, \mathrm{B}$-complex, $\mathrm{C}$ and $\mathrm{E}$. In general, the vitamin content is rich in honeyberry while vitamin $\mathrm{C}$ is rich in blackcurrant and strawberry (Pantelidis et al., 2007). These vitamins reduce the oxidative stress and acts as antioxidant by radical scavenging. This ultimately boosts the immune system (Hakala et al., 2003). Both macronutrients and micronutrients are found in this fruit. They are rich in iron, phosphorus and calcium along with manganese, sodium and copper. These minerals play a vital role in maintaining the regular functioning of the body systems. They look after the bones and teeth along with membrane functioning. Minerals in berries maintain the hormonal balance in the body along with electrolyte balance (Hardisson et al., 2001). Anthocyanins are a group of flavonoids that are found in most of the berries including blueberries, blackberries, raspberries, cranberries, strawberries, blackcurrants, grapes, etc. They offer protection against various ailments (Zierau et al., 2002). They behave as anti-inflammatory, antioxidant and anticancer agents (Xue et al., 2002). Presence of ellagic acid makes the fruit a good antimicrobial and antiviral agent. They also show chemopreventive activities (Bushman et al., 2004).
Similar benefits are expressed due to the presence of gallic acid and quercetin. They also act as a strong antioxidant. Due to the presence of high quantities of quercetin, raspberries are used for the treatment of cold and flu. They also exhibit anticancerous properties. High tannin content makes it a good antiseptic agent. Berry varieties including raspberries, blueberries, cranberries, and strawberries possess great amounts of vitamin $\mathrm{C}$ that provide immense immune health for the protection of body against pathogenic organisms. Flavonoids like bioactive compounds provide protection from microbes in liver, kidney, etc. (WHO, 2002). Flavonoids including anthocyanin exhibit anti-inflammatory activities and provide protection against CVD (Quettier-Deleue et al., 2003). The ellagic acid shows antiproliferative action that destroys the cancer cell growth (Valente et al.,2011). Cranberries, cloudberries, red raspberries, strawberries, and bilberries possess antimicrobial properties against harmful pathogens. The ellagitannins present in these berries provide this effect by behaving as an anti-adherent compound which prevents attaching and colonising of the pathogens. They are proven to be effective against Salmonella spp., Staphylococcus spp., Helicobacter spp., and Bacillus spp., Escherichia spp., Clostridium spp., and Campylobacter spp. Apart from non-adherence, many techniques are followed by these phenolic compounds to showcase the antimicrobial action. Some of them are destabilization of cytoplasmic membrane, inhibition of extracellular microbial enzymes and depriving the microbes of the growing conditions (Puupponen-Pimiä et al., 2005). The order of antimicrobial activity of berries against gram-negative bacteria: 'cloudberry $>$ raspberry $>$ strawberry $>$ lingonberry $>$ blueberry $>$ cranberry $>$ sea buckthorn berry $>$ blackcurrant' (Nohynek et al., 2006).

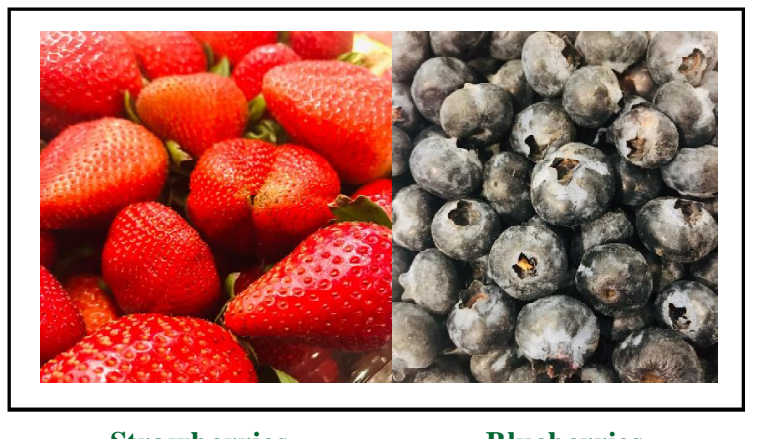

Cranberry juice comprises $65 \%$ of proanthocyanidins that reduces and eliminates the adhesion property of the bacteria to the body (Burger et al., 2000). This is used in the treatment of plaque in oral health. Black raspberries that have high quantities of quercetin show antitumor activities that attribute to the presence of flavonoids (Rossi et al., 2007). These berries also reduce the size of lesion in cancer. Similar activities are found in blueberries and strawberries (Stoner et al., 2010). Anthocyanins show anti-tumour activities. Grape powder intrudes Wnt pathway that prevents cancer cell development. Epicatechin, a flavanol decreases the risk of colorectal cancer. A healthy gut microbiota is essential to maintain good immune responses. The vital good bacteria are "Firmicutes, Bacteroidetes, Actinobacteria, Proteobacteria, Verrucomicrobia, and Fusobacteria". Studies suggest that consumption of $25 \mathrm{~g}$ of blueberry extract daily increase the lactobacilli and bifidobacteria. These bacteria improve the immune health (Vendrame et al., 2011). Human 
trials of consumption of dried-grapes for 9 weeks increased the concentrations of lymphocyte (NK, T, and B cells) (Amagase et $a l ., 2009)$. Consumption of a mix of berries increases the effectiveness of the functioning of the immune system. Elderberries (Sambucus spp.) are a type of berry that is widely grown in Europe, Asia, etc. This kind of berries possess high flavonoids that shows antioxidant activities, antitumor properties, antibacterial and antiviral properties (Walker et al., 2013). Wolfberry (Lycium barbarum L.) are also known as Goji berries. These berries show protective effect against respiratory and pulmonary ailments (Chen et al., 2018).

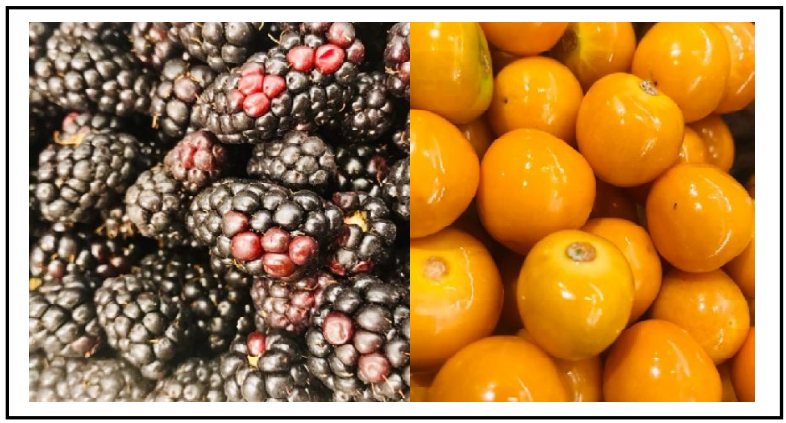

Blackberries

Golden berries

Emblic berries (Phyllanthus emblica L.) locally known as Amla has numerous health benefits due to the presence of varied flavonoids and tannins (Rao et al., 2013). Lingonberries (Vaccinium vitis-idaea L.) native to Scandinavia, possess a variety of phenolic groups that shows protective effects against many disorders. They show antioxidant, antimicrobial and anti-inflammatory activities (Afrin et al., 2016). Sea buckthorn berries possess huge quantities of vitamin $\mathrm{C}$ that boosts the immune health of the body. Grapes (Vitis vinifera L.) are rich in phenolic acids and flavonoids, especially resveratrol that shows high antioxidant activities and anti-inflammatory activities (Afrin et al., 2016). Pomegranates (Punica granatum L.) has high quantities of polyphenols in their peel and husk that attributes to its anti-inflammatory activities. They also contain punicalgin and ellagitannin that induces apoptosis (Olajide et al., 2014). They also show anticancerous and antimicrobial properties. Strawberries contain various phytochemicals like ellagic acid, catechin and quercetin and vitamins like $\mathrm{C}$ and $\mathrm{E}$ that shows protection against cancer and CVD. Studies suggest that consumption of strawberries enhance the immune response by stimulation the production of immune cells (Zunino et al., 2014). Kiwi is a kind of berry that has the second most antioxidant content after plums; this property attributes to anti-inflammatory activity and antiallergic activity (An et al., 2016). Blueberries (Vaccinium corymbosum L.) and mangosteen (Garcinia mangostana L.) also possess various bioactive components like any other berry. They also induce the production of immune cells. They also show antiinflammatory actions by the production of NO and inflammatory cytokines (Bumrungpert et al., 2010). Raspberries (Rubus sp.) exhibit anti-inflammatory actions due to the presence of rich anthocyanin content in them (Shin et al., 2014). Both blackberry and cranberry comprise of anthocyanin and cyanidins, ellagitannins and quercetins that give them the rich antioxidant capabilities and anti-inflammatory activity (Skupień and Oszmiański, 2004). Other berries like blackcurrants, jamun berries and barberries also show various health promoting interests.

\section{Conclusion}

The coronavirus that has taken a toll in everybody's life can be controlled and prevented by a nutrient-rich diet. Evidences suggest that people with weak immune system are attacked and the recovery rate of the latter is very minimal. Hence, boosting the immune health with fruits and vegetables is the prime aim of prevention. This review article highlights the nutraceuticals and their mechanisms to improve the general health. Vitamin and mineral rich fruits reduces the risk of various chronic ailments that directly or indirectly helps avoiding the deadly virus. Dietary fibre acts as anti-inflammatory agent. Vitamin $\mathrm{A}$ and $\mathrm{C}$ are a good source of antioxidants. Vitamins A, C, B, E and minerals like zinc, selenium, etc., positively impact the immune functions. Various phytochemicals synergistically increase the immunomodulatory functions. Intake of probiotic improves the gut microbiota that enhances the immune health. Combining the dietary benefits, overall health can be improved by an active lifestyle which keeps the body away from any kind of disease.

\section{Acknowledgements}

The authors wish to acknowledge the Department of Science and Technology for their financial support extended for the project SEED/TITE/2019/77.

\section{Conflict of interest}

The authors declare that there are no conflicts of interest relevant to this article.

\section{References}

Abeysinghe, D.C.; Li, X.; Sun, C.; Zhang, W.; Zhou, C. and Chen, K. (2007). Bioactive compounds and antioxidant capacities in different edible tissues of citrus fruit of four species. Food Chem., 104:13381344.

Abuajah, C.I.; Ogbonna, A.C. and Osuji, C.M. (2015). Functional components and medicinal properties of food: A review. J. Food Sci. Technol., 52:2522-2529.

Adiani, V.; Gupta, S. and Variyar, P. S. (2020). Microbial quality assessment of minimally processed pineapple using GCMS and FTIR in tandem with chemometrics. Scientific Reports, 10(6203):1-9.

Afrin, S.; Giampieri, F.; Gasparrini, M.; Forbes-Hernandez, T. Y.; Varela-Lopez, A.; Quiles, J. L.; Mezzetti, B. and Battino, M. (2016). Chemopreventive and therapeutic effects of edible berries: A focus on colon cancer prevention and treatment. Molecules, 21(2): 169 .

Al-Farsi, M.; Alasalvar, C.; Morris, A.; Baron, M. and Shahidi, F. (2005). Compositional and sensory characteristics of three native sundried date (Phoenix dactylifera L.) varieties grown in Oman. J. Agric. Food Chem., 53(19):7586-7591.

Alkhatib, A.; Tsang, C.; Tiss, A.; Theeshan, B.; Arefanian, H.; Barake, R.; Khadir, A. and Tuomilehto, J. (2017). Functional Foods and lifestyle Approaches for Diabetes Prevention and Management Nutrients, 9:13-17.

Alpert, P.T. (2017). The role of vitamins and minerals on the immune system. Home Health Care Manag. Pract., 29:199-202.

Altap, S.; Kýzýl, G.; Kýzýl, M.; Ketani, A. and Haris, P.I. (2011). Protective effect of diyarbakýr watermelon juice on carbon tetrachlorideinduced toxicity in rats. Food and Chemical Toxicology, 49(9): 2433-2438. 
Amagase, H.; Sun, B. and Nance, D.M. (2009). Immunomodulatory effects of a standardized Lycium barbarum fruit juice in Chinese older healthy human subjects. J. Med. Food., 12:1159-1165.

An, X.; Lee, S. G.; Kang, H.; Heo, H. J.; Cho, Y. S. and Kim, D. O. (2016). Ant oxidant and anti-inflammatory effects of various cultivars of kiwi berry (Actinidia arguta) on lipopolysaccharide-stimulated RAW 264.7 cells. Journal of Microbiology and Biotechnology, 26(8):1367-1374

Anagnostopoulou, M. A.; Kefalas, P.; Papageorgiou, V. P.; Assimopoulou, A. N. and Boskou, D. (2006). Radical scavenging activity of various extracts and fractions of sweet orange peel (Citrus sinensis). Food Chemistry, 94(1):19-25.

Antunes-Ricardo, M.; Gutiérrez-Uribe, J.; Martínez Vitela, C. and Serna-Saldivar S. (2015). Topical anti-inflammatory effects of isorhamnetin glycosides isolated from opuntia Ficus indica. Bio. Med. Research International, pp:10-15.

Anusooriya, P.; Malarvizhi, D.; Kanniappan Gopalakrishnan, V. and Devaki, K. (2014). Antioxidant and antidiabetic effect of aqueous fruit extract of Passiflora ligularis Juss. on Streptozotocin induced diabetic rats. Int. Sch. Res. Not., 10:212-227.

Arora, R.; Kaur, M. and Gill, N.S. (2011). Antioxidant activity and pharmacological evaluation of Cucumis melo var. agrestis methanolic seed extract. Research Journal of Phytochemistry, 5(3):146155 .

Arscott, S.A.; Howe, J.A.; Davis, C.R. and Tanumihardjo, S.A. (2010). Carotenoid profiles in provitamin A-containing fruits and vegetables affect the bioefficacy in Mongolian gerbils. Exp. Biol. Med., 235:839848 .

Assirey E.A. (2015). Nutritional composition of fruit of 10 date palm (Phoenix dactylifera L.) cultivars grown in Saudi Arabia. Journal of Taibah University for Science, 9(1):75-79.

Barnett, J.B.; Hamer, D.H. and Meydani, S.N. (2010). Low zinc status: A new risk factor for pneumonia in the elderly? Nutr. Rev., 68:30-37.

Brown, L.; Poudyal, H. and Panchal, S.K. (2015), Foods as the treatment of obesity. Obes. Rev., 16:914-941.

Bulotta, S.; Celano, M.; Lepore, S. M.; Montalcini, T.; Pujia, A. and Russo, D. (2014). Beneficial effects of the olive oil phenolic components oleuropein and hydroxytyrosol: Focus on protection against cardiovascular and metabolic diseases. Journal of Translational Medicine, 12(1):101-119.

Bumrungpert, A.; Kalpravidh, R. W.; Chuang, C. C.; Overman, A.; Martinez, K.; Kennedy, A. and McIntosh, M. (2010). Xanthones from mangosteen inhibit inflammation in human macrophages and in human adipocytes exposed to macrophage-conditioned media. Journal of Nutrition, 140(4):842-847.

Burger, O.; Ofek, I.; Tabak, M.; Weiss, EI.; Sharon, N. and Neeman, I. (2000). A high molecular mass constituent of cranberry juice inhibits helicobacter pylori adhesion to human gastric mucus. FEMS Immunol. Med. Microbiol., (4):295-301.

Bushman, B.S.; Phillips, B.; Isbell, T.; Ou, B.; Crane, J.M. and Knapp, S.J. (2004) Chemical composition of caneberry (Rubus spp.) seeds and oils and their antioxidant potential. J. Agric. Food Chem., 26:7982-7.

Butera, D.; Tesoriere, L.; Di Gaudio, F.; Bongiorno, A.; Allegra, M.; Pintaudi, A.M.; Kohen, R. and Livrea, M.A. (2002). Antioxidant activities of sicilian prickly pear (Opuntia ficus indica) fruit extracts and reducing properties of its betalains: Betanin and indicaxanthin. J. Agric. Food Chem., 50(23):6895-6901.
Campos, D.; Betalleluz-Pallardel, I.; Chirinos, R.; Aguilar-Galvez, A.; Noratto, G. and Pedreschi, R. (2012). Prebiotic effects of yacon (Smallanthus sonchifolius Poepp. and End), a source of fructooligosaccharides and phenolic compounds with antioxidant activity. Food Chemistry, 135:1592-1599.

Çandir, E.; Yetiir, H.; Karaca, F. and Üstün, D. (2013). Phytochemical characteristics of grafted watermelon on different bottle gourds (Lagenaria siceraria) collected from the mediterranean region of turkey. Turkish Journal of Agriculture and Forestry, 37(4):443456.

Carr, A.C.; Shaw, G.M.; Fowler, A.A. and Natarajan, R. (2015). Ascorbatedependent vasopressor synthesis: A rationale for vitamin C administration in severe sepsis and septic shock? Crit. Care, 19: 418 .

Castellano, J.M.; Guinda, A.; Delgado, T.; Rada, M. and Cayuela, J.A. (2013). Biochemical basis of the antidiabetic activity of oleanolic acid and related pentacyclic triterpenes. Diabetes, 62(6):1791-1799.

Chaira, N.; Smaali, M.I.; Martinez-Tomé, M.; Mrabet, A.; Murcia, M.A. and Ferchichi, A. (2009). Simple phenolic composition, flavonoid contents and antioxidant capacities in water-methanol extracts of Tunisian common date cultivars (Phoenix dactylifera L.). Int. J. Food Sci. Nutr., 60(7):316-329.

Chen, L.; Li, W.; Qi, D. and Wang, D. (2018). Lycium barbarum polysaccharide protects against LPS-induced ARDS by inhibiting apoptosis, oxidative stress, and inflammation in pulmonary endothelial cells. Free Radical Research, 52(4):480-490.

Codoñer-Franch, P. and Valls-Bellés, V. (2010). Citrus as functional foods. Curr. T. Nutraceut. Res., 8:173-183.

Constans, J.; Bennetau-Pelissero, C.; Martin, J.; Rock, E.; Mazur, A.; Bedel, A. and Bérard, A. M. (2015). Marked antioxidant effect of orange juice intake and its phytomicronutrients in a preliminary randomized cross-over trial on mild hypercholesterolemic men. Clinical Nutrition, 34(6):1093-1100.

Cossu, A.; Posadino, A.M.; Giordo, R.; Emanueli, C.; Sanguinetti, A.M. and Piscopo, A. (2012). Apricot melanoidins prevent oxidative endothelial cell death by counteracting mitochondrial oxidation and membrane depolarization. PLoS ONE, 7(11):310-341.

Costa, D. C.; Costa, H. S.; Albuquerque, T. G.; Ramos, F.; Castilho, M. C. and Sanches-Silva, A. (2015). Advances in phenolic compounds analysis of aromatic plants and their potential applications. Trends in Food Science and Technology, 45(2):336-354.

Cremonini, E.; Bettaieb, A.; Haj, F. G.; Fraga, C. G. and Oteiza, P. I. (2016). Epicatechin improves insulin sensitivity in high fat diet-fed mice. Archives of Biochemistry and Biophysics, 599:13-21.

De Souza Mda, S.; Barbalho, S.M.; Damasceno, D.C.; Rudge, M.V.; de Campos, K.E.; Madi, A.C.; Coelho, B.R.; Oliveira, R.C.; de Melo, R.C. and Donda, V.C. (2012). Effects of Passiflora edulis (yellow passion) on serum lipids and oxidative stress status of Wistar rats. J. Med. Food., 15(1):78-82.

Dharmarathna, S.L.C.A.; Wickramasinghe, S.; Waduge, R.N.; Rajapakse, R.P.V.J. and Kularatne, S.A.M. (2013). Does Carica papaya leaf-extract increase the platelet count? An experimental study in a murine model. Asian Pac. J. Trop. Biomed., 3:720-724.

Dittakan, K.; Theera-Ampornpunt, N. and Boodliam, P. (2018). Non-destructive grading of pattavia pineapple using texture analysis. 21st International Symposium on Wireless Personal Multimedia Communications (WPMC):144-149.

Dragovic-Uzelac, V.; Levaj, B.; Mrkic, V.; Bursac, D. and Boras, M. (2007). The content of polyphenols and carotenoids in three apricot cultivars depending on stage of maturity and geographical region. Food Chemistry, 102(3):966-975. 
El Hadrami, Abdel and Al-Khayri, Jameel (2012). Socioeconomic and traditional importance of date palm. Emir. J. Food. Agric., 24:10.

Elleuch, M.; Besbes, S.; Roiseux, O.; Blecker, C.; Deroanne, C.; Drira, N. and Attia, H. (2008). Date flesh: Chemical composition and characteristics of the dietary fibre. Food Chemistry, 111(3):676-682.

Ezikanyi, D. N.; Nnamani, C. V. and Ihejirika, J. N. (2016). Qualitative phytochemical analysis and in vitro fungal activities of Citrus aurantifolia L. and Carica papaya L. leaves extracts on pathogenic fungi. Journal of Pharmacy and Biological Sciences, 11:68-72.

Fattouch, S.; Caboni, P.; Coroneo, V.; Tuberoso, C.; Angioni,A.; Dessi, S.; Marzouki, N. and Cabras, P. (2008). Comparative analysis of polyphenolic profiles and antioxidant and antimicrobial activities of tunisian pome fruit pulp and peel Aqueous acetone extracts. J. Agric Food Chem., 56(3):1084-1090.

Flores, G.; Dastmalchi, K.; Dabo, A. J.; Whalen, K.; Pedraza-Peñalosa, P.; Foronjy R. F. and Kennelly, E.J. (2012). Antioxidants of therapeutic relevance in COPD from the neotropical blueberry, Anthopterus wardii. Food Chemistry, 131(1):119-125.

Frei, B.; Birlouez-Aragon, I. and Lykkesfeldt, J. (2012). Authors' perspective: What is the optimum intake of vitamin $\mathrm{C}$ in humans? Crit. Rev. Food Sci., 52:815-829.

Gogna, N.; Hamid, N. and Dorai, K. (2015). Metabolomic profiling of the phytomedicinal constituents of Carica papaya L. leaves and seeds by $1 \mathrm{H}$ NMR spectroscopy and multivariate statistical analysis Journal of Pharmaceutical and Biomedical Analysis, 115:74-85.

Gonzalez-Molina, E.; Domingues-Perles, R.; Moreno, D.A. and Garcia, V.C. (2010). Natural bioactive compounds of Citrus limon for food and health. J. Pharm. Biomed. Anal., 51:327-345.

Gorinstein, S.; Leontowicz, H.; Leontowicz, M.; Jesion, I.; Namiesnik, J.; Drzewiecki, J. and Trakhtenberg, S. (2011). Influence of two cultivars of persimmon on atherosclerosis indices in rats fed cholesterolcontaining diets: Investigation in vitro and in vivo. Nutrition, 27(7):838-846

Gu, H.; Li, C.; Xu, Y.; Hu, W.; Chen, M. and Wan, Q. (2008). Structural features and antioxidant activity of tannin from persimmon pulp. Food Research International, 41(2):208-217.

Güçlü, K.; Altun, M.; Özyürek, M.; Karademir, S.E. and Apak, R. (2006) Antioxidant capacity of fresh, sun and sulphited dried Malatya apricot (Prunus armeniaca) assayed by CUPRAC, ABTS/TEAC and folin methods. International Journal of Food Science and Technology, 41:76-85.

Gupta, S.C.; Tyagi, A.K.; Deshmukh-Taskar, P.; Hinojosa, M.; Prasad, S. and Aggarwal, B.B. (2014). Downregulation of tumor necrosis factor and other proinflammatory biomarkers by polyphenols. Archives of Biochemistry and Biophysics, 559:91-99.

Habauzit, V.; Sacco, S.M.; Gil-Izquierdo,A.; Trzeciakiewicz,A.; Morand, C.; Barron, D.; Pinaud, S.; Offord, E. and Horcajada, M.N. (2011). Differential effects of two citrus flavanones on bone quality in senescent male rats in relation to their bioavailability and metabolism. Bone, 49:11081116.

Hakala, M.; Lapveteläinen, A.; Huopalahti, R.; Kallio, H. and Tahvonen, R. (2003). Effects of varieties and cultivation conditions on the composition of strawberries. Journal of Food Composition and Analysis, 16(1): $67-80$.

Hardisson, A.; Rubio, C.; Baez, A.; Martin, M.; Alvarez, R. and Diaz, E. (2001). Mineral composition of the banana (Musa acuminata) from the island of tenerife. Food Chemistry, 73(2):153-161.

Hole, A. S.; Grimmer, S.; Jensen, M. R.and Sahlstrøm, S. (2012). Synergistic and suppressive effects of dietary phenolic acids and other phytochemicals from cereal extracts on nuclear factor kappa B activity. Food Chemistry, 133(3):969-977.
Hooper, S.J.; Lewis, M.A.O.; Wilson, M.J. and Williams, D.W. (2010). Antimicrobial activity of citrox bioflavonoid preparations against oral microorganisms. Brit. Dent. J., 210(22):211-227.

Huang, C.; Wang, Y. and Li, X. (2020). Clinical features of patients infected with 2019 novel coronavirus in Wuhan, China. The Lancet, 395(10223): 497-506.

Huang, L.; Guan, T.; Qian, Y.; Huang, M.; Tang, X.; Li, Y. and Sun, H. (2011). Anti-inflammatory effects of maslinic acid, a natural triterpene, in cultured cortical astrocytes via suppression of nuclear factorkappa B. European Journal of Pharmacology, 672(1):169-174.

Huijskens, M.J.; Walczak, M.; Sarkar, S.; Atrafi, F.; Senden-Gijsbers, B.L.; Tilanus, M.G.; Bos, G.M.; Wieten, L. and Germeraad, W.T. (2015). Ascorbic acid promotes proliferation of natural killer cell populations in culture systems applicable for natural killer cell therapy. Cytotherapy, 17:613-620.

Indhuleka, A.; Sanjana, R.; Janet, J. and Ragavi, V. (2021). Importance of vegetables as healthier diet in the management of COVID-19 pandemic. Ann. Phytomed., 9(2):62-79.

Jaafar, R.A.; Rahman, A.R.B.A.; Mahmod, N.Z.C. and Vasudevan, R. (2009). Proximate analysis of dragon fruit (Hylocereus polyrhizus). Amer. J. App. Sci., 6(7):1341-1346.

Jabri Karoui, I. and Marzouk, B. (2013). Characterization of bioactive compounds in Tunisian bitter orange (Citrus aurantium L.) peel and juice and determination of their antioxidant activities. Biomed. Res. Int., 13:345-415.

Janzantti, N. S.; Macoris, M. S.; Garruti, D. S. and Monteiro, M. (2012). Influence of the cultivation system in the aroma of the volatile compounds and total antioxidant activity of passion fruit. LWT - Food Science and Technology, 46(2):511-518.

Kan, H.; Stevens, J.; Heiss, G.; Rose, K.M. and London, S.J. (2008). Dietary fiber, lung function, and chronic obstructive pulmonary disease in the atherosclerosis risk in communities study. Am. J. Epidemiol., 167: 570-578.

Kang, J.H., Sung, M.K., Kawada, T., Yoo, H., Kim, Y.K., Kim, J.S., and Yu, R. (2005) Soybean saponins suppress the release of proinflammatory mediators by LPS-stimulated peritoneal macrophages. Cancer Lett., 230:219-227.

Karamac, M.; Kosinska, A. and Pegg, R.B. (2005). Comparison of radicalscavenging activities for selected phenolic acids. Polish J. Food Nutri, Sci., 14:165-170.

Katsuura, S.; Imamura, T.; Bando, N. and Yamanishi, R. (2009). Beta-carotene and beta-cryptoxanthin but not lutein evoke redox and immune changes in RAW264 murine macrophages. Mol. Nutr. Food Res., 53:1396-1405.

Kazemi, A.; Noorbala, A.A.; Azam, K.; Eskandari, M.H. and Djafarian, K. (2019). Effect of probiotic and prebiotic vs placebo on psychological outcomes in patients with major depressive disorder: A randomized clinical trial. Clinical Nutrition, 38:522-528.

Kendall, P. and Ryan, E. (2009). Defined benefit plans: The quiet evolution. Journal of Compensation and Benefits, 25(1):42-46.

Kevers, C.; Pincemail, J.; Tabart, J.; Defraigne, J.O. and Dommes, J. (2011). Influence of cultivar, harvest time, storage conditions, and peeling on the antioxidant capacity and phenolic and ascorbic acid contents of apples and pears. J. Agric. Food Chem., 59(11):6165-6171.

Khanal, P.; Oh, W.K.; Thuong, P.T.; Cho, S.D. and Choi, H.S. (2010). 24 hydroxyursolic acid from the leaves of the diospyros kaki (Persimmon) induces apoptosis by activation of AMP-activated protein kinase. Planta Med., 76(7):689-693. 
Kim, C.H.; Park, M.K.; Kim, S.K. and Cho, Y.H. (2014). Antioxidant capacity and anti inflammatory activity of lycopene in watermelon. Int. J. Food Sci. Technol., 49:2083-2091.

Knekt, P.; Kumpulainen, J.; Järvinen, R.; Rissanen, H.; Heliövaara, M.; Reunanen, A.; Hakulinen, T and Aromaa, A. (2002). Flavonoid intake and risk of chronic diseases, The American Journal of Clinical Nutrition, 76(3):560-568

Krakauer, T. (2002). The polyphenol chlorogenic acid inhibits staphylococcal exotoxin-induced inflammatory cytokines and chemokines. Immunopharmacology and Immunotoxicology, 24(1):113-119.

Lata, B. and Tomala, K. (2007). Apple peel as a contributor to whole fruit quantity of potentially healthful bioactive compounds. Cultivar and year implication. J. Agric. Food Chem., 55(26):10795-10802.

Leontowicz, H.; Leontowicz, M.; Gorinstein, S.; Martin-Belloso, O. and Trakhtenberg, S. (2007). Apple peels and pulp as a source of bioactive compounds and their influence on digestibility and lipid profile in normal and atherogenic rats. Medycyna Weterynaryjna, 63:1434 1436 .

Lester, G. (1997). Melon (Cucumis melo L.) fruit nutritional quality and health functionality, Hort. Technology, Horttech., 7(3):222-227.

López-Vargas, J. H.; Fernández-López, J.; Pérez-Álvarez, J. A.and Viuda-Martos, M. (2013). Chemical, physicochemical, technological, antibacterial and antioxidant properties of dietary fiber powder obtained from yellow passion fruit (Passiflora edulis var. flavicarpa) co-products Food Research International, 51(2):756-763.

Marko, M.G.; Ahmed, T.; Bunnell, S.C.; Wu, D.; Chung, H.; Huber, B.T. and Meydani, S.N. (2007). Age-associated decline in effective immune synapse formation of CD4(+) $\mathrm{T}$ cells is reversed by vitamin $\mathrm{E}$ supplementation. J. Immunol., 178:1443-1449.

Marotta, F.; Weksler, M.; Naito, Y.; Yoshida, C.; Yoshioka, M. and Marandola, P. (2006). Nutraceutical supplementation: Effect of a fermented papaya preparation on redox status and DNA damage in healthy elderly individuals and relationship with GSTM1 genotype. A randomized, placebo-controlled, cross-over study. Ann. N. Y. Acad. Sci., 1067:400-407.

Marques, S.S.F.; Libonati, R.M.F.; Sabaa-Srur, A.U.O.; Luo, R.; Shejwalkar, P.; Hara, K. and Smith, R.E. (2016). Evaluation of the effects of passion fruit peel flour (Passiflora edulis fo. flavicarpa) on metabolic changes in HIV patients with lipodystrophy syndrome secondary to antiretroviral therapy. Revista Brasileira De Farmacognosia, 26(4):420-426

McCullough, F.S.; Northrop-Clewes, C.A. and Thurnham, D.I. (1999). The effect of vitamin A on epithelial integrity. Proc. Nutr. Soc., 58:289-293.

Mehra, M.; Pasricha, V. and Gupta, R. K. (2015). Estimation of nutritional, phytochemical and antioxidant activity of seeds of muskmelon (Cucumis melo) and watermelon (Citrullus lanatus) and nutritional analysis of their respective oils. J. Pharmacogn. Phytochem., 3(6):98-102.

Meydani, S.N.; Han, S.N. and Wu, D. (2005). Vitamin E and immune response in the aged: Molecular mechanisms and clinical implications. Immunol. Rev., 205:269-284.

Montanher,A. B.; Zucolotto, S. M.; Schenkel, E. P. and Fröde, T. S. (2007). Evidence of anti-inflammatory effects of passiflora edulis in an inflammation model. Journal of Ethnopharmacology, 109(2):281-288.

Mosekilde, L. (2005). Vitamin D and the elderly. Clin. Endocrinol. (Oxf.), 62:265-281

Mueller, D.; Triebel, S.; Rudakovski, O. and Richling, E. (2013). Influence of triterpenoids present in apple peel on inflammatory gene expression associated with inflammatory bowel disease (IBD). Food Chemistry, 139(1):339-346.
Mullauer, F.B.; Kessler, J.H. and Medema, J.P. (2010). Betulinic acid, a natural compound with potent anticancer effects. Anticancer Drugs, 21(3):215-227.

Myhara, H. M., Karkala, J. and Taylor, M.S. (1999). The composition of maturing omani dates. J. Sci. Food Agric., 47:471-479.

Naz, A.; Butt, M. S.; Sultan, M. T; Qayyum, M. M. N. and Niaz, R. S. (2014). Watermelon lycopene and allied health claims. EXCLI Journal, 13:650-666.

Nishino, H.; Murakoshi, M.; Tokuda, H. and Satomi, Y. (2009). Cancer prevention by carotenoids. Arch. Biochem. Biophys., 483:165168 .

Nohynek, L.J.; Alakomi, H.L.; Kähkönen, M.P.; Heinonen, M.; Helander, I.M.; Oksman-Caldentey, K. M. and Puupponen-Pimiä, R.H. (2006). Berry phenolics: Antimicrobial properties and mechanisms of action against severe human pathogens. Nutr. Cancer, 54(1):18-32.

Olajide, O. A.; Kumar,A.; Velagapudi, R.; Okorji, U. P. and Fiebich, B. L. (2014). Punicalagin inhibits neuroinflammation in LPS-activated rat primary microglia. Molecular Nutrition and Food Research, 58(9): 1843-1851.

Oloyede, O.I. (2005). Chemical profile of unripe pulp of Carica papaya. Pakistan Journal of Nutrition, 4(6):379-381

Oomah, B.D. and Mazza, G. (2000). Functional foods. The Wiley Encyclopedia of Science and Technology, 2(2):1176-1182.

Ortiz, J.M. (2002). Botany in citrus: The genus citrus; Dugo, G., Di Giacomo, A., Eds.; Taylor and Francis: New York, NY, USA, pp:16-35.

Ostlund, R.E. (2002). Phytosterols in human nutrition. Annu. Rev. Nutr., 22(1)

Otsuki, N.; Dang, N. H.; Kumagai, E.; Kondo, A.; Iwata, S.and Morimoto, C. (2010). Aqueous extract of Carica papaya leaves exhibits antitumor activity and immunomodulatory effects. Journal of Ethnopharmacology, 127(3):760-767.

Oude Griep, L.M.; Stamler, J.; Chan, Q.; Van Horn, L.; Steffen, L.M.; Miura, K.; Ueshima, H.; Okuda, N.; Zhao, L.; Daviglus, M.L. and Elliott, P. (2013). INTERMAP research group. Association of raw fruit and fruit juice consumption with blood pressure: The INTERMAP study. Am. J. Clin. Nutr., 97(5):1083-1091.

Owoyele, B.V.; Adebukola, O.M. and Funmilayo, A.A. (2008). Antiinflammatory activities of ethanolic extract of Carica papaya leaves. Inflammo. pharmacol., 16:168-173.

Palacios, C. (2006). The role of nutrients in bone health, from A to Z. Crit. Rev. Food Sci., 46:621-628.

Pan, M.H.; Chen, W.J.; Lin-Shiau, S.Y.; Ho, C.T. and Lin, J.K. (2002). Tangeretin induces cell-cycle G1 arrest through inhibiting cyclin-dependent kinases 2 and 4 activities as well as elevating Cdk inhibitors p21 and p27 in human colorectal carcinoma cells. Carcinogenesis, 23: $1677-1684$

Pandey, S.; Cabot, P. J.; Shaw, P. N. and Hewavitharana, A. K. (2016). Antiinflammatory and immunomodulatory properties of Carica papaya. Journal of Immunotoxicology, 13(4):590-602.

Pandey, S.; Walpole, C.; Cabot, P. J.; Shaw, P. N.; Batra, J. and Hewavitharana, A. K. (2017). Selective anti-proliferative activities of Carica papaya leaf juice extracts against prostate cancer. Biomedicine and Pharmacotherapy, 89:515-523.

Pantelidis, G. E.; Vasilakakis, M.; Manganaris, G. A. and Diamantidis, G. (2007). Antioxidant capacity, phenol, anthocyanin and ascorbic acid contents in raspberries, blackberries, red currants, gooseberries and cornelian cherries. Food Chemistry, 102(3):777-783. 
Piotrowska, H.; Kucinska, M. and Murias, M. (2012). Biological activity of piceatannol: Leaving the shadow of resveratrol. Mutation Research/Reviews in Mutation Research, 750(1):60-82.

Poudel-Tandukar, K. and Chandyo, R.K. (2016). Dietary B Vitamins and Serum C-Reactive Protein in Persons With Human Immunodeficiency Virus Infection: The Positive Living With HIV (POLH) Study. Food Nutr. Bull., 37:517-528.

Poulose, S.M.; Harris, E.D. and Patil, B.S. (2005). Citrus limonoids induce apoptosis in human neuroblastoma cells and have radical scavenging activity. J. Nutr., 135:870-877.

Prasad, N. R.; Karthikeyan,A.; Karthikeyan, S. and Reddy, B. V. (2011). Mol.Cel Biochem, pp:34.

Puupponen-Pimiä, R.; Nohynek, L.; Alakomi, H. and Oksman-Caldentey, K. (2005). Bioactive berry compounds - novel tools against human pathogens. Applied Microbiology and Biotechnology, 67(1):818.

Quettier-Deleu, C.; Voiselle, G.; Fruchart, J. C.; Duriez, P.; Teissier, E.; Bailleul, F. and Trotin, F. (2003). Hawthorn extracts inhibit LDL oxidation. Die Pharmazie-An International Journal of Pharmaceutical Sciences, 58(8):577-581.

Rad, A. H. K.; Falahi, E. and Ebrahimzadeh, F. (2014). Recent patents on physical, mineral and organic acid composition of golden delicious and red delicious apples (Malus $\times$ Domestica borkh) grown in the west of Iran. Recent Patents on Food, Nutrition and Agriculture, 6(2):93-99.

Ramadan, M.F.; Sitohy, M.Z. and Moersel, J.T. (2008). Solvent and enzymeaided aqueous extraction of goldenberry (Physalis peruviana L.) pomace oil: Impact of processing on composition and quality of oil and meal. Eur. Food Res. Technol., 226:1445-1458.

Rao, A.V. and Rao, L.G. (2007). Carotenoids and human health. Pharmacological Research, 55(3):207-216.

Rao, T. P.; Okamoto, T.; Akita, N.; Hayashi; T., Kato-Yasuda, N. and Suzuki, K. (2013). Amla (Emblica officinalis Gaertn.) extract inhibits lipopolysaccharide-induced procoagulant and pro-inflammatory factors in cultured vascular endothelial cells. British Journal of Nutrition, 110(12):2201-2206

Reiland, H. and Slavin, J. (2015). Systematic review of pears and health. Nutrition Today, 50(6):301-305.

Ren, H.; Hao, J.; Liu, T.; Zhang, D.; Lv, H.; Song, E. and Zhu, C. (2016). Hesperetin suppresses inflammatory responses in lipopolysaccharide-induced RAW 264.7 cells via the inhibition of NF- $\mathrm{KB}$ and activation of Nrf2/ HO-1 pathways. Inflammation, 39(3):964-973.

Rivera Pastrana, D.M.; Yahia, E.M. and González Aguilar, G.A. (2010). Phenolic and carotenoid profiles of papaya fruit (Carica papaya L.) and their contents under low temperature storage. J. Sci. Food Agric., 90:2358-2365

Rossi, M.; Garavello, W.; Talamini, R.; Negri, E.; Bosetti, C.; Dal Maso, L.; Lagiou, P.; Tavani, A.; Polesel, J.; Barzan, L.; Ramazzotti, V.; Franceschi, S. and La Vecchia, C. (2007). Flavonoids and the risk of oral and pharyngeal cancer: A case-control study from Italy. Cancer Epidemiol Biomarkers Prev., 16(8):1621-5.

Sadek, K.M., (2012). Antioxidant and immunostimulant effect of Carica papaya Linn. aqueous extract in acrylamide intoxicated rats. Acta Inform. Medica., 20:180-185.

Saeed, F.; Nadeem, M.; Ahmed, R.S.; Tahir Nadeem, M.; Arshad, M.S. and Ullah, A. (2016). Studying the impact of nutritional immunology underlying the modulation of immune responses by nutritional compounds: A review. Food Agric. Immunol., 27:205-229.
Sass-Kiss, A.; Kiss, J.; Milotay, P.; Kerek, M. M. and Toth-Markus, M. (2005). Differences in anthocyanin and carotenoid content of fruits and vegetables. Food Research International, 38(8):1023-1029.

Serra, A. T.; Poejo, J.; Matias, A. A.; Bronze, M. R. and Duarte, C. M. M. (2013). Evaluation of Opuntia spp. derived products as antiproliferative agents in human colon cancer cell line (HT29). Food Research International, 54(1):892-901.

Sha, S.; Li, J.; Wu, J. and Zhang, S. (2011). Characteristics of organic acids in the fruit of different pear species. African Journal of Agricultural Research, 6(10):2403-2410.

Shin, J. S.; Cho, E. J.; Choi, H. E.; Seo, J.H.; An, H. J.; Park, H. J.; Cho, Y.W. and Lee, K. T. (2014). Anti-inflammatory effect of a standardized triterpenoidrich fraction isolated from Rubus coreanus on dextran sodium sulfate-induced acute colitis in mice and LPS-induced macrophages. Journal of Ethnopharmacology, 158:291-300.

Singh, P.; Shukla, R.; Prakash, B.; Kumar, A.; Singh, S.; Mishra, P.K. and Dubey, N.K. (2010). Chemical profile, antifungal, antiaflatoxigenic and antioxidant activity of Citrus maxima Burm and Citrus sinensis (L.) Osbeck essential oils and their cyclic monoterpene, DLlimonene. Food Chem. Toxicol., 48:1734-1740.

Siriwardhana, N.; Kalupahana, N. S.; Cekanova, M.; LeMieux, M.; Greer, B. and Moustaid-Moussa, N. (2013). Modulation of adipose tissue inflammation by bioactive food compounds. The Journal of Nutritional Biochemistry, 24(4):613-623.

Skupieñ, K. and Oszmiañski, J. (2004). Comparison of six cultivars of strawberries (fragaria $\mathrm{x}$ ananassa duch.) grown in northwest Poland. European Food Research and Technology, 219(1):66-70.

Song, H.; Zheng, Z.; Wu, J.; Lai, J.; Chu, Q. and Zheng, X. (2016). White pitaya (Hylocereus undatus) juice attenuates insulin resistance and hepatic steatosis in diet-induced obese mice. PLoS ONE, 11(2):112.

Stoner, G.D.; Wang, L.S.; Seguin, C.; Rocha, C.; Stoner, K.; Chiu, S. and Kinghorn, A.D. (2010). Multiple berry types prevent $\mathrm{N}$-nitrosomethyl benzylamine-induced esophageal cancer in rats. Pharm. Res., 6:1138-45.

Strati, I.F.; Sinanoglou, V.J.; Kora, L.; Miniadis-Meimaroglou, S. and Oreopoulou, V. (2012). Carotenoids from Foods of Plant, Animal and Marine Origin: An Efficient HPLC-DAD Separation Method. Foods, 1:5265

Szeto, Y.T.; Tomlinson, B. and Benzie, I.F.F. (2002). Total antioxidant and ascorbic acid content of fresh fruits and vegetables: Implications for dietary planning and food preservation. Brit. J. Nutr., 87:5559.

Takuji, T.; Takahiro, T.; Mayu, T. and Toshiya, K. (2012). Cancer chemoprevention by citrus pulp and juices containing high amounts of $\beta$-cryptoxanthin and hesperidin. J. Biomed. Biotechnol., pp:110 .

Tan, J.; McKenzie, C.; Potamitis, M.; Thorburn, A.N.; Mackay, C.R. and Macia, L. (2014). The role of short-chain fatty acids in health and disease. Adv. Immunol., 121:91-119.

Tesoriere, L.; Butera, D.; Pintaudi, A.M.; Allegra, M. and Livrea, M.A. (2004). Supplementation with cactus pear (Opuntia ficus - indica) fruit decreases oxidative stress in healthy humans: A comparative study with vitamin C. Am. J. Clin. Nutr., 80(2):391-395.

Thilavech, T.; Ngamukote, S.; Belobrajdic, D.; Abeywardena, M. and Adisakwattana, S. (2016). Cyanidin-3-rutinoside attenuates methylglyoxal-induced protein glycation and DNA damage via carbonyl trapping ability and scavenging reactive oxygen species. BMC Complementary and Alternative Medicine, 16(1):111.

Tian, H.; Zhang, H.; Zhan, P. and Tian, F. (2011). Composition and antioxidant and antimicrobial activities of white apricot almond (Amygdalus communis L.) oil. Eur. J. Lipid Sci. Technol., 113:1138-1144. 
Valente, A.; Albuquerque, T.G.; Sanches-Silva, A. and Costa, H.S. (2011). Ascorbic acid content in exotic fruits: A contribution to produce quality data for food composition databases. Food Research International, 44(7):2237-2242

Vayalil, P.K. (2002). Antioxidant and antimutagenic properties of aqueous extract of date fruit (Phoenix dactylifera L. Arecaceae). Journal of Agricultural and Food Chemistry., 50(3):610-617.

Vayalil, P.K. (2012). Date fruits (Phoenix dactylifera Linn): An emerging medicinal food. Crit. Rev. Food Sci. Nutr., 52(3):249-271.

Vendrame, S.; Guglielmetti, S.; Riso, P.; Arioli, S.; Klimis-Zacas, D. and Porrini, M. (2011). Six-week consumption of a wild blueberry powder drink increases bifidobacteria in the human gut. J. Agric. Food Chem., 59(24):12815-20

Vikram,A.; Uckoo, R. M.; Murthy, K.N.; Patil, B.S. and Jayaprakasha, G.K.(2015) Citrus: A treasure trove of health-promoting phytochemicals. In Jayaprakasha, G.K., Bhimanagouda, S., Patil, B.S., (Eds.), Nutraceuticals and Functional Foods-Chemistry and Health Promoting Properties of Fruits and Beverages Involved in Focused Toward Prevention of Chronic Diseases: Encyclopedia of Life Support Systems. Oxford: Eolss Publishers Co. Ltd, pp:143-177.

Vinita, V. and Punia, D. (2016). Nutritional composition of fruit of four date palm (Phoenix dactylifera L.) cultivars grown in Haryana, India. Asian J. Dairy Food Res., 35:331-334.

Walker, J. M.; Maitra, A.; Walker, J.; Ehrnhoefer-Ressler, M. M.; Inui, T. and Somoza, V. (2013). Identification of Magnolia officinalis L. bark extract as the most potent antiinflammatory of four plant extracts The American Journal of Chinese Medicine, 41(3):531-544.

Wang, A.Y.; Zhou, M.Y. and Lin, W.C. (2011). Antioxidative and antiinflammatory properties of Citrus sulcata extracts. Food Chem., 124:958-963.

Wedick, N.M.; Pan, A.; Cassidy, A.; Rimm, E.B.; Sampson, L.; Rosner, B.; Willett W.; Hu, F.B.; Sun, Q. and van Dam, R.M. (2012). Dietary flavonoid intakes and risk of type 2 diabetes in US men and women. Am. J. Clin. Nutr., 95(4):925-933.

Weickert, M.O. and Pfeiffer, A.F. (2008). Metabolic effects of dietary fibe consumption and prevention of diabetes. J. Nutr., 138(3):439442 .

Wintergerst, E.S.; Maggini, S. and Hornig, D.H. (2006). Immune-enhancing role of vitamin $\mathrm{C}$ and zinc and effect on clinical conditions. Ann. Nutr. Meta., 50:85-94

Wintergerst, E.S.; Maggini, S. and Hornig, D.H. (2007). Contribution of selected vitamins and trace elements to immune function. Ann. Nutr. Metab., 51:301-323.
Worbs, T.; Hammerschmidt, S.I. and Forster, R. (2017). Dendritic cell migration in health and disease. Nat. Rev. Immunol., 17:30-48.

World Health Organization (2002). The world health report 2002: Reducing risks, promoting healthy life. World Health Organization, pp:20.

Wu, G.; Collins, J.K.; Perkins-Veazie, P.; Siddiq, M.; Dolan, K.D.; Kelly, K.A.; Heaps, C.L. and Meininger, C.J. (2007). Dietary supplementation with watermelon pomace juice enhances arginine availability and ameliorates the metabolic syndrome in Zucker diabetic fatty rats. J. Nutr., 137(12):2680-2685.

Xue, R.; Huang, G. and Mao, Y. (2002). Studies on phosphorus removal by chlorella pyrenoidosa with modified PVA-sulfate immobilization method. Zhongguo Huanjing Kexue/China Environmental Science, 22(4):351.

Yang, M.; Wang, C.; Chen, N.; Ho, W.; Lu, F. and Tseng, T. (2014). Luteolin enhances paclitaxel-induced apoptosis in human breast cancer MDA-MB-231 cells by blocking STAT3. Chemico-Biological Interactions, 213:60-68

Yi, Z.; Yu, Y.; Liang, Y. and Zeng, B. (2008). In vitro antioxidant and antimicrobial activities of the extract of pericarpium citri reticulatae of a new citrus cultivar and its main flavonoids. LWT Food Science and Technology, 41(4):597-603.

Zdrojewicz, Z.; Chorbinska,' J.; Biezynski,' B. and Krajewski, P. (2018). Healthpromoting properties of pineapple. Pediatria i Medycyna Rodzinna, 14(2):133-142.

Zhang, J.; Gu, H.; Zhang, L.; Tian, Z.; Zhang, Z; Shi, X. and Ma, W. (2011). Protective effects of apricot kernel oil on myocardium against ischemia-reperfusion injury in rats. Food and Chemical Toxicology, 49(12):3136-3141.

Zhang, S.; Hu, H.; Wang, L.; Liu, F. and Pan, S. (2018). Preparation and prebiotic potential of pectin oligosaccharides obtained from citrus peel pectin. Food Chemistry, 244:232-237.

Zhu, N.; Zhang, D. and Wang, W. (2020). A novel coronavirus from patients with pneumonia in China, 2019. New England Journal of Medicine, 382(8):727-733.

Zierau, O.; Bodinet, C.; Kolba, S.; Wulf, M. and Vollmer, G. (2002). Antiestrogenic activities of Cimicifuga racemosa extracts. The Journal of Steroid Biochemistry and Molecular Biology, 80(1): $125-130$.

Zunino, S. J.; Peerson, J. M.; Freytag, T. L.; Breksa, A. P.; Bonnel, E. L.; Woodhouse, L. R. and Storms, D. H. (2014). Dietary grape powder increases IL-1 $\beta$ and IL-6 production by lipopolysaccharide-activated monocytes and reduces plasma concentrations of large LDL and large LDLcholesterol particles in obese humans. British Journal of Nutrition, $112(3): 369-380$ 